\title{
LA REPRESENTATIVIDAD SINDICAL COMO HERRAMIENTA DE PROMOCIÓN SINDICAL EN COLOMBIA*
}

\section{TRADE UNION REPRESENTATIVENESS AS A TOOL FOR TRADE UNION PROMOTION IN COLOMBIA}

\author{
Pierre-Henri Cialti** \\ Jairo Villegas-Arbeláez $* * *$ \\ Fecha de recepción: 3 de mayo de 2016 \\ Fecha de aceptación: 20 de marzo de 2017 \\ Disponible en línea: 30 de noviembre de 2017
}

\section{Para citar este artículo/To cite this article}

Cialti, Pierre-Henri \& Villegas-Arbeláez, Jairo, La representatividad sindical como herramienta de promoción sindical en Colombia, 135 Vniversitas, 53-98 (2017). https://doi.org/10.11144/Javeriana.vj135.rshp

doi:10.11144/Javeriana.vj135.rshp

* Artículo de reflexión.

** Profesor de derecho del trabajo y de la seguridad social, Universidad de Vigo, España. Anteriormente, docente-investigador, Corporación Universitaria del Caribe-Cecar, Sincelejo, Colombia. Orcid: orcid.org/0000-0003-3298-2312. Doctor en derecho, Universidad de Valencia, España; Universidad de Toulouse-I, Francia. Maestría en derecho del trabajo y de la seguridad social, Universidad de Toulouse-I, Francia. Contacto: pierrecialti@gmail.com

*** Antiguo Profesor de derecho administrativo laboral, Facultad de Derecho, Universidad de los Andes, Bogotá, Colombia. Antiguo profesor en posgrado, Departamento de Derecho del Trabajo, Universidad Externado de Colombia, Bogotá. Orcid: 0000-0003-0946-8585. Abogado, Universidad Libre, Bogotá. Contacto: ofivillegas@hotmail.com 


\section{RESUMEN}

Este artículo tiene como objetivo central analizar y criticar la situación del sindicalismo en Colombia, mediante el uso del derecho internacional y comparado, al revisar el marco conceptual de la noción de representatividad, de sus criterios de reconocimiento y de sus prerrogativas. En este sentido, se procede a un estudio analítico del dispositivo legal en la materia respecto al marco constitucional con el fin de demostrar la falta de adecuación de aquel, respecto al diseño propuesto por la Constitución política colombiana de 1991. Igualmente, se adopta una perspectiva comparada que enriquece la reflexión al ofrecer elementos de entendimiento del significado y de las funciones de la noción de representatividad sindical. La reflexión pone de relieve el desajuste entre los marcos constitucional y legal en materia de promoción sindical y considera la introducción de la noción de representatividad sindical en el ordenamiento jurídico como una herramienta central de la promoción del sindicalismo en Colombia.

Palabras clave: Libertad sindical; representatividad sindical; Organización Internacional del Trabajo, OIT; democracia 


\section{ABSTRACT}

This paper aims to analyze and criticize the situation of trade unionism in Colombia throughout the use of international and comparative law, analyzing the conceptual framework of the concept of representativeness, the recognition criteria of representativeness and the prerogatives of the same. In this sense, we proceed to an analytical study of the legal device regarding the constitutional framework in order to demonstrate the inadequacy of that in respect to that design proposed by the Colombian Constitution of 1991. Similarly, a comparative perspective is adopted to enrich the reflection offering elements for the understanding of the meaning and how of the notion of union representation works. Reflection leads to highlight the mismatch between the constitutional and legal frameworks for trade union advocacy and to consider the introduction of the notion of union representation in the legal system as a central tool of promotion of trade unionism in Colombia.

Keywords: Freedom of Association; trade union representativeness; ILO; democracy

\section{SUMARIO}

INTRODUCCIÓN. I. CONSIDERACIONES PREVIAS.- $A$. Representación sindical vs. representatividad sindical.- $B$. La representación institucional como función originaria de la representatividad sindical.- C. El marco colombiano.- II. LOS CRITERIOS DE MEDICIÓN DE LA REPRESENTATIVIDAD SINDICAL.- $A$. La afiliación sindical.- B. Las carencias de la afiliación sindical.- C. Los otros criterios.- III. LAS PRERROGATIVAS INHERENTES A LA REPRESENTATIVIDAD SINDICAL.- $A$. La compatibilidad de la noción de representatividad con el principio de igualdad.- B. La negociación colectiva y la aplicación de la convención colectiva.- C. Otras funciones.- Conclusión.- Bibliografía. 


\section{INTRODUCCIÓN}

Este trabajo no pretende abordar los problemas generales del sindicalismo en Colombia, sino centrarse en una noción generalmente vinculada a este: la representatividad sindical, presente en derecho internacional y en numerosos países.

En el contexto colombiano, resulta llamativo que el Código Sustantivo del Trabajo (en adelante, CST) ${ }^{1}$ no se refiere en ningún momento a esta noción. Así, la premisa del trabajo consiste en considerar que uno de los factores de debilidad del movimiento sindical en Colombia es la ausencia de un marco legal que promocione el movimiento sindical, mediante el uso de la noción de representatividad, a pesar de que, desde la perspectiva constitucional, el sindicato ha de desempeñar un papel importante en la formación del Estado Social de Derecho.

Desde el punto de vista metodológico, el análisis del modelo legal conduce a referirse al derecho internacional, en especial a las posiciones de la Organización Internacional del Trabajo, OIT, y al derecho comparado para tomar la medida de las posibilidades que puede ofrecer el uso de la noción de representatividad como herramienta de fomento del movimiento sindical. Obviamente, el análisis de las disposiciones legales y reglamentarias debe efectuarse desde el prisma de la Constitución Política de Colombia de 1991 (en adelante, $\mathrm{CPC})^{2}$.

Para resolver estas cuestiones, conviene en primer lugar formular algunas consideraciones previas para definir el marco conceptual de la noción de representatividad sindical, es decir, distinguirla de la noción de representación de derecho común y conocer su función. En segundo lugar, abordamos los criterios que permiten reconocer a un sindicato el carácter de representativo. En tercer y último lugar, es oportuno tratar las prerrogativas concretas que le son tradicionalmente inherentes, haciendo hincapié en la negociación colectiva.

1 Colombia, Decreto Ley 3743 de 1950, Código Sustantivo del Trabajo, 27.622 Diario Oficial, 7 de junio de 1951. Disponible en: http://www.secretariasenado.gov.co/senado/basedoc/codigo_sustantivo_trabajo.html

2 Colombia, Constitución Política, versión corregida 116 Gaceta Constitucional, 20 de julio de 1991. Disponible en: http://www.secretariasenado.gov.co/senado/basedoc/constitucion_politica_1991. html 


\section{CONSIDERACIONES PREVIAS}

\section{A. Representación sindical vs. representatividad sindical}

Las relaciones de trabajo se caracterizan por la existencia de una dimensión colectiva que, rompiendo con el dogma liberal, se intercala entre el legislador y la ciudadanía, es decir, entre la ley y el contrato. Esta singularidad conduce a establecer especialidades en torno a mecanismos de representación jurídica de los intereses de los trabajadores que se materializa por cuerpos intermediarios: las organizaciones sindicales. Así, al hilo de las palabras del profesor Jesús Cruz-Villalón, "los fenómenos de representación sindical [...] se encuentran a caballo entre los mecanismos de representación civil o privada y los instrumentos de representación política o pública"3. Su constitución, bajo la forma asociativa - es decir, de carácter privado con representación civil-, y su finalidad de representar intereses privados responden a su vertiente privada. Sin embargo, estas asociaciones representan igualmente intereses colectivos. El interés colectivo se distingue de la suma de los intereses de los miembros de un sindicato y del interés general ${ }^{4}$. El sindicato defiende un interés propio, el interés colectivo de la profesión cuya defensa constituye la base de la acción sindical, su razón de ser $^{5}$. Esta consideración permite subrayar su dimensión pública y recuerda la ruptura con el dogma liberal antes señalada. El reconocimiento del interés colectivo se acompañó de un poder atribuido a los sindicatos para representar a los trabajadores mediante prerrogativas legalmente previstas, poder jurídicamente materializado por la noción de representatividad $^{6}$. En todo caso, el surgimiento de estos cuerpos intermediarios — que son las estructuras sindicales - responde a

3 Jesús CRUZ-VILLALÓN, La representatividad sindical y empresarial en las relaciones laborales y en el sistema politico español, 1 Relaciones Laborales, 151-196 (2005). Disponible en: https://idus. us.es/xmlui/handle/11441/41763?locale-attribute=es

4 Para Mario de la Cueva, los sindicatos "son sociedades humanas naturales (...) son cuerpos sociales reales (...) que persiguen fines determinados, que no son una simple suma de intereses individuales". Mario de la Cueva, Nuevo derecho mexicano del trabajo, Tomo II, 256 (Porrúa, México, 1986).

5 Federico Navarro-Nieto, La representatividad sindical, 24 (Ministerio de Trabajo y de la Seguridad Social, Madrid, 1993).

6 Federico Navarro-Nieto, La representatividad sindical, 24 (Ministerio de Trabajo y de la Seguridad Social, Madrid, 1993). 
una exigencia política, económica y social para dar herramientas y canalizar el conflicto latente y consustancial a las relaciones de trabajo.

Estas consideraciones explican la necesidad de superar los mecanismos de representación meramente civilista, de derecho privado. En este marco, conviene distinguir los conceptos de representación sindical y de representatividad sindical. Según el profesor Antonio Ojeda-Avilés, podemos entender como representación sindical "al conjunto de facultades de obrar en nombre e interés de los afiliados que se basan en el mecanismo jurídico-privado del apoderamiento de tipo asociativo" y como representatividad sindical, "al conjunto de poderes de obrar en interés general de los trabajadores reconocidos por el poder público a determinadas organizaciones sindicales en base a un procedimiento publificado de selección"7. En efecto, la representatividad sindical es externa a la autonomía colectiva y constituye un "título de legitimidad" a las organizaciones sindicales ${ }^{8}$ atribuido por el Estado 9 , una herramienta jurídica a su disposición ${ }^{10}$, que le permite descartar interlocutores válidos, tanto en las relaciones de trabajo con los empleadores, como en las relaciones políticas con los poderes públicos. El fomento del diálogo entre representantes de los trabajadores y las asociaciones empresariales o las administraciones públicas que deriva de ello, permite superar la confrontación y hacer converger los intereses para fortalecer las economías nacionales en un contexto mundializado.

7 Antonio Ojeda-Avilés, La representatividad sindical como excepción, 1 Relaciones Laborales, 238-252 (1992). Por su parte, María Emilia Casas distingue entre la representación voluntaria de derecho privado, y la representatividad o, mejor, la mayor representatividad, "como noción a la que los distintos ordenamientos sindicales miran para seleccionar y ordenar la acción de los sindicatos, reduciendo su pluralidad y brindándoles un tratamiento jurídico desigual en función de aquella (pluralismo institucionalista proporcional y mayoritario)". María Emilia CASAs-BAAmonde, Representatividad y mayor representatividad de los sindicatos en España. ¿Un modelo en crisis?, 33 Civitas. Revista Española de Derecho del Trabajo, 71-86 (1988).

8 Jean-Maurice Verdier, Sur la relation entre représentation et représentativité syndicales, 1 Droit Social, 5-10 (1991). El autor estima que la "representatividad es un modo de habilitación, la de los más aptos a representar".

9 La doctrina subraya que la representatividad constituye "un título de relevancia del orden profesional para el orden estatal”. STAMATINA YANNAKOUROU, L'Etat, l'autonomie collective et le travailleur: étude comparée du droit italien et du droit français de la représentativité syndicale (Librairie générale de droit et de jurisprudence, LGDJ, Paris, 1995).

10 JoAQuín García-Murcia, Organizaciones sindicales y empresariales más representativas: posición jurídica y dimensión política, 67 (Ministerio de Trabajo y de la Seguridad Social, Madrid, 1987). El autor distingue dos dimensiones a la representatividad: por un lado, es una herramienta jurídica y, por otro lado, es una cualidad jurídica. 


\section{B. La representación institucional como función originaria de la representatividad sindical}

La noción de representatividad tiene su origen en la Constitución de la OIT de 1919, que menciona a "las organizaciones profesionales más representativas de empleadores o de trabajadores"11. No se trata de contemplar la actividad sindical en cada uno de los países miembros, sino de establecer herramientas que permiten la designación de "delegados y consejeros técnicos no gubernamentales" ante los diferentes órganos de la OIT. Sin lugar a dudas, la utilización de la noción de representatividad por parte de la OIT remite a su función racionalizadora del sistema de relaciones de trabajo y permite a los poderes públicos, nacionales o internacionales en este caso, proceder a la selección de interlocutores válidos.

En este punto, conviene distinguir la noción de representatividad y la de mayor representatividad. Ciertamente, ambas nociones se refieren a un proceso de selección de sindicatos que permite detectar organizaciones dotadas de una capacitad de representación especial. Sin embargo, cuando se habla de sindicatos más representativos, se contemplan organizaciones cuyo ámbito de actuación es global, es decir, extendido al conjunto del territorio de un país ${ }^{12}$ y al conjunto de los sectores profesionales. La representatividad simple se refiere más bien a un ámbito concreto, más reducido tanto territorial como funcionalmente.

Para entender esta diferencia, resulta oportuno referirse a la finalidad primaria de la noción de representatividad que aparece con claridad en las normas de la OIT. Surgió para identificar organizaciones sindicales válidas y capaces de ser interlocutores de los poderes públicos. Así, tiene una función instrumental y práctica clara, ya que, desde el punto de vista logístico y funcional, sería inviable que todas las organizaciones de trabajadores y empleadores de los Estados miembros estén presentes en los diferentes órganos de la OIT. La presencia de organizaciones sindicales destacadas en estos órganos se refiere a lo que se denomina representación

11 Organización Internacional del Trabajo, OIT, Constitución de la Organización Internacional del Trabajo de 1919, artículo 3, párrafo 5 (Oficina Internacional del Trabajo, Ginebra, 2010). Disponible en: http://www.ilo.org/dyn/normlex/es/f?p=1000:62:0::NO:62:P62_LIST_ENTRIE_ID:2453907:NO

12 Puede haber mayor representatividad en un territorio reducido. Por ejemplo, en España, se establece en regiones (en una comunidad autónoma). 
institucional que, tanto en el ámbito internacional como en el nacional, permite la "gobernabilidad del sistema político"13, para incluir representantes de trabajadores en los procesos de decisión relativos a cuestiones inherentes a las relaciones de trabajo. Así, la representatividad se revela "indispensable a una sana práctica del pluralismo sindical"14. Ahora bien, la doctrina subraya que esta relación entre Estado y sindicatos presenta el riesgo de fomentar el neocorporativismo mediante un doble intercambio: reconocimiento como interlocutores privilegiados por parte del Estado ${ }^{15}$ a determinados sindicatos contra el compromiso de aquellos sindicatos de neutralizar y controlar los conflictos sociales y respetar lo pactado ${ }^{16}$.

\section{E1 marco colombiano}

Colombia reconoce el pluralismo sindical, lo que plantea el problema de la efectiva representación de los trabajadores. El cuadro constitucional relativo al actor sindical resulta explícito en cuanto a su papel. El artículo 1 de la CPC reza: "Colombia es un Estado social de derecho, [...] fundada [...] en el trabajo". El artículo 39 se refiere a la libertad sindical, al derecho de los trabajadores y empleadores "a constituir sindicatos o asociaciones, sin intervención del Estado”. El artículo 55 párrafo 2 remite al Estado el deber de "promover la concertación y los demás medios para la solución pacífica de los conflictos colectivos de trabajo". El artículo 56 párrafo 3 prevé que "una comisión permanente integrada por el Gobierno, por representantes de los empleadores y de los trabajadores, fomentará las buenas relaciones laborales, contribuirá a la solución de los conflictos colectivos de trabajo y concertará las

13 Fernando VAldÉs DAL-RÉ, Representación y representatividad sindicales en España, 14-15 Relaciones Laborales, 55-69 (1988).

14 Jean-Maurice Verdier, Syndicats et droit syndical. Traité de droit du travail, Vol. I, 486 (2 ed., Guillaume-Henri Camerlynck, dir., Dalloz, Paris, 1987). En todo caso, es indudable que la representatividad responde a exigencias sociales, económicas y jurídicas. MARÍA EMILIA CASAs-BAAMONDE, Representatividad y mayor representatividad de los sindicatos en España. ¿Un modelo en crisis?, 33 Civitas. Revista Española de Derecho del Trabajo, 71-86 (1988).

15 En este sentido, el profesor Ojeda subraya que la "sustitución de los criterios privatísticos por los de índole pública se produce con el pleno asentimiento de los sindicatos, halagados por su nuevo papel no subalterno". ANTONIO OJEDA-AviLÉs, La representatividad sindical como excepción, 1 Relaciones Laborales, 238-252 (1992).

16 FeRnAndo VALdÉs DAL-RÉ, Representación y representatividad sindicales en España, 14-15 Relaciones Laborales, 55-69, 55 y ss. (1988). 
políticas salariales y laborales. La ley reglamentará su composición y funcionamiento". Igualmente, el artículo 103 párrafo 2 afirma: "el Estado contribuirá a la organización, promoción y capacitación de las asociaciones profesionales, cívicas, sindicales [...], sin detrimento de su autonomía con el objeto de que constituyan mecanismos democráticos de representación en las diferentes instancias de participación, concertación, control y vigilancia de la gestión pública que se establezcan". Igualmente, además de la capacidad de autoorganización de la autonomía colectiva vía el reconocimiento de la libertad sindical del artículo 39, conviene apuntar que la CPC "garantiza" el derecho a la negociación colectiva ${ }^{17}$ y el derecho de huelga ${ }^{18}$. En este sentido, el triángulo equilátero al cual se refiere Mario de la Cueva incluye la capacidad de autoorganización (libertad de asociación sindical), de autonormación (negociación colectiva) y la capacidad de autotutela (huelga) ${ }^{19}$. Finalmente, según los términos de los artículos 55, 56.3 y 103 párrafo 2, incumbe al Estado cumplir un papel activo en el fomento de la participación de los sindicatos como "representantes de los trabajadores", como "mecanismos democráticos de representación en las diferentes instancias de participación, concertación, control y vigilancia de la gestión pública que se establezcan".

Este marco constitucional permite poner de relieve, por una parte, que el trabajo representa un elemento clave y fundamental del Estado. Por otra, conduce a afirmar que el sindicato es, por esencia, el interlocutor clave en la materia. Así, se plasma en el texto constitucional la publificación de las organizaciones sindicales como sujeto sociopolítico que ha de concretarse no solo en mecanismos de representación institucional, lo cual garantiza la representación de todos los trabajadores pero también una actuación proactiva de los poderes públicos que deben asegurar herramientas de potenciación del papel de las organizaciones sindicales. Por consiguiente, parece obvio que se han de establecer mecanismos que permitan identificar los interlocutores sindicales válidos capaces de llevar a cabo, desde una dimensión política y axiológica, el texto constitu-

17 Artículo 55 CPC: "Se garantiza el derecho de negociación colectiva para regular las relaciones laborales, con las excepciones que señale la ley".

18 Artículo 56 CPC: "Se garantiza el derecho de huelga, salvo en los servicios públicos esenciales definidos por el legislador".

19 Mario de la Cueva, Nuevo derecho mexicano del trabajo, Tomo II, 216-217 (Porrúa, México, 1986). 
cional. En este marco, tendría que resultar ineludible el uso de la noción de representatividad. Pues bien, la transposición del marco constitucional al plano legal demuestra que ningún elemento tiende a promover el papel del sindicato, en especial mediante el uso de la noción de representatividad. Aún más, veremos cómo el marco legal conduce más bien a obstaculizar la transposición real del papel del sindicato tal como plasma la CPC.

Respecto a la participación institucional, los sindicatos considerados más representativos integran la Comisión Permanente de Concertación de Políticas Salariales y Laborales. A pesar de disponer de un amplio abanico de competencias ${ }^{20}$, esta comisión tiene una actividad muy limitada, reducida en la práctica a la negociación del salario mínimo, que desemboca generalmente en un desacuerdo y en la actuación unilateral del Estado ${ }^{21}$. En todo caso, consideramos que el riesgo de neocorporativismo surge con mucha más fuerza por la instauración de un foro sindical desproporcionado respecto a la protección del resto de los trabajadores vinculados a un sindicato, por la existencia de los contratos sindicales o por los vínculos entre determinados sindicalistas y el mundo político.

Tras estas consideraciones previas, a continuación nos proponemos abordar elementos de entendimiento de la noción de representatividad sindical desde una perspectiva teórica, para aportar elementos de derecho internacional y de derecho comparado, y poder proyectarla a la realidad colombiana.

20 Por ejemplo, "Fomentar las buenas relaciones laborales; fijar de manera concertada la política salarial; fijar de manera concertada la política laboral mediante planes estratégicos sobre estos asuntos; definir estrategias de desarrollo para los trabajadores independientes y de la economía solidaria; preparar los proyectos de la ley en materias sujetas a su competencia, para que el gobierno los presente al Congreso de la República"; o resolver consultas formuladas por el Gobierno. Colombia, Ley 278 de 1996, 30 de abril, Comisión permanente de concertación de políticas salariales y laborales creada por el artículo 56 de la Constitución Política, artículo 2, 42.783 Diario Oficial, 10 de mayo de 1996. Disponible en: http://www.secretariasenado.gov.co/senado/basedoc/ley_0278_1996.html

21 HÉctor VÁsquez-Fernández, La negociación colectiva en Colombia, en Estrategias sindicales para una mayor y mejor negociación colectiva en América Latina y Caribe. Campaña libertad sindical, negociación colectiva y autorreforma sindical, 258-291 (CSA-CSI, Confederación Sindical de Trabajadores y Trabajadoras de las Américas, São Paulo, 2013). Disponible en: http://www.ilo.org/ wcmsp5/groups/public/---ed_dialogue/---actrav/documents/publication/wcms_230682.pdf. En este sentido, un autor propone el reforzamiento del tripartismo para remediar las carencias de la negociación colectiva. EdUARdo FERNÁNDEZ-Alonso, El juez laboral y la jurisprudencia constitucional sobre el derecho de asociación, 34 Revista de Derecho Público, Universidad de los Andes, 3-22 (2015). Disponible en: https://derechopublico.uniandes.edu.co/components/com_revista/archivos/ derechopub/pub511.pdf 


\section{LOS CRITERIOS DE MEDICIÓN DE LA REPRESENTATIVIDAD SINDICAL}

En el ámbito internacional, no se estableció definición de la representatividad, lo que permitió a cada país determinar los criterios nacionales para designar sus delegados en la OIT. Ahora bien, estos criterios deben cumplir ciertas exigencias que garantizan que el Estado no pueda condicionar el reconocimiento de la representatividad a criterios arbitrarios o subjetivos. Así, el Comité de Libertad Sindical del Consejo de Administración de la OIT considera que "los criterios en que se inspire la distinción entre organizaciones más o menos representativas tienen que ser de carácter objetivo y fundarse en elementos que no ofrezcan posibilidad de parcialidad o abuso"22, y que "deben existir en la legislación criterios objetivos, precisos y previamente establecidos para determinar la representatividad de una organización de empleadores o de trabajadores, y dicha apreciación no podría dejarse a la discreción de los gobiernos"23.

A pesar de ello, es preciso subrayar que numerosas referencias se hacen al criterio de la afiliación sindical que ha sido, por otra parte, el criterio escogido en Colombia en determinados casos. No obstante, este criterio presenta por esencia carencias y conduce a abordar la oportunidad de recurrir a otros criterios.

22 Organización Internacional del Trabajo, OIT, La libertad sindical - Recopilación de decisiones y principios del Comité de Libertad Sindical del Consejo de Administración de la OIT, párrafo 347 (5 ed., OIT, Ginebra, 2006). Disponible en: http://www.ilo.org/global/docs/WCMS_090634/lang--es/ index.htm

23 Organización Internacional del Trabajo, OIT, La libertad sindical - Recopilación de decisiones y principios del Comité de Libertad Sindical del Consejo de Administración de la OIT, párrafo 348 ( $5^{\mathrm{a}}$ ed., OIT, Ginebra, 2006). Podemos citar también la Recomendación 159, "sobre los procedimientos para determinar las condiciones de empleo en la administración pública", que es norma reglamentaria del Convenio 151, que preceptúa que "para el reconocimiento de las organizaciones de empleados públicos [...] debería basarse en criterios objetivos y preestablecidos respecto del carácter representativo de esas organizaciones [...]”. Organización Internacional del Trabajo, OIT, Recomendación 159 sobre las relaciones de trabajo en la administración pública, numerales 1.1. y 2 (Ginebra, 1978). Disponible en: http://www.ilo.org/dyn/normlex/es/f?p=NORMLEXPUB:12100:0:: NO::P12100_INSTRUMENT_ID:312497. En igual sentido, Organización Internacional del Trabajo, OIT, Recomendación 163 sobre el fomento de la negociación colectiva, numeral 3.b (Ginebra, 1981). Disponible en: http://www.ilo.org/dyn/normlex/es/f?p=NORMLEXPUB:12100:0::NO::P12100_ ILO_CODE:R163 


\section{A. La afiliación sindical}

En el ámbito internacional, se hacen numerosas menciones a un criterio específico: la afiliación, que se ha convertido en el criterio de referencia para la OIT. Así, se refiere a "la distinción [...] entre los diferentes sindicatos de acuerdo con su grado de representatividad [...] carácter que se deriva de un número más elevado de afiliados" 24 , al "porcentaje a efectos de determinar el nivel de representación" 25 o a "un sistema de representación sindical para ejercer los derechos sindicales colectivos que se basan en el grado de afiliación sindical"26.

En el ámbito nacional, Colombia se refiere al criterio de la afiliación sindical en varias ocasiones.

La Ley 278 de 1996 relativa a la Comisión Permanente de Concertación de Políticas Salariales y Laborales establece, en su artículo 5 literal c modificado por el artículo 1 de la Ley 990 de 2005, que en representación de los trabajadores formarán parte de la comisión "Tres (3) representantes, con sus respectivos suplentes personales, designados o removidos por las Confederaciones Sindicales más representativas del país, determinadas con base en el número de afiliados que cada una de estas posea al momento de la elección, según el censo que en tal sentido elabore el Ministerio de la Protección Social"27. A partir de un censo sindical, se determina

24 Organización Internacional del Trabajo, OIT, La libertad sindical - Recopilación de decisiones y principios del Comité de Libertad Sindical del Consejo de Administración de la OIT, párrafo 346 ( $5^{\mathrm{a}}$ ed., OIT, Ginebra, 2006).

25 Organización Internacional del Trabajo, OIT, La libertad sindical - Recopilación de decisiones y principios del Comité de Libertad Sindical del Consejo de Administración de la OIT, párrafo 356 ( $5^{\mathrm{a}}$ ed., OIT, Ginebra, 2006).

26 Organización Internacional del Trabajo, OIT, La libertad sindical - Recopilación de decisiones y principios del Comité de Libertad Sindical del Consejo de Administración de la OIT, párrafo 349 ( $5^{\text {a }}$ ed., OIT, Ginebra, 2006).

27 Colombia, Ley 278 de 1996, 30 de abril, Comisión permanente de concertación de políticas salariales y laborales creada por el artículo 56 de la Constitución Política, 42.783 Diario Oficial, 10 de mayo de 1996. Colombia, Ley 990 de 2005, por la cual se modifica el literal c) del artículo 5 de la Ley 278 de 1996, 46.046 Diario Oficial, 29 de septiembre de 2005. Disponible en: http://www. secretariasenado.gov.co/senado/basedoc/ley 0990 2005.html. Es preciso aclarar que mediante la Ley 1444 de 2011, el Ministerio de la Protección Social fue escindido en dos, lo que condujo a su transformación en Ministerio de Trabajo y a la creación del Ministerio de Salud y de Protección Social. Colombia, Ley 1444 de 2011, por medio de la cual se escinden unos Ministerios, se otorgan precisas facultades extraordinarias al Presidente de la República para modificar la estructura de la Administración Pública y la planta de personal de la Fiscalía General de la Nación y se dictan otras disposiciones. 48.059 Diario Oficial, 4 de mayo de 2011. Disponible en: http://www.secretariasenado. gov.co/senado/basedoc/ley_1444_2011.html 
cuáles son las tres organizaciones con más afiliados que integran la Comisión ${ }^{28}$. Supuesto eso, es necesario contar con un censo adecuadamente actualizado y creíble. Pues bien, a sabiendas de que el anterior censo tuvo lugar en 1983 y de que el Ministerio de Trabajo convocó a finales de 2015 otro "censo" de carácter dispositivo ${ }^{29}$, para que cada sindicato real o ficticio, dijera cuál era el número de sus afiliados, es legítimo dudar de la veracidad y de la credibilidad de los datos manejados actualmente por ese Ministerio.

Igualmente, el artículo 9 del Decreto 160 de $2014^{30}$ remite a la autonomía sindical la formación de la comisión de negociación en el sector público y, en caso de desacuerdo, establece el principio de proporcionalidad en función del número de afiliados.

Finalmente, en materia de negociación colectiva en el sector privado o para los trabajadores oficiales, el Decreto 89 de 2014 en su artículo 1 in fine dispone que "los sindicatos con menor grado de representatividad proporcional al número de sus afiliados, tendrán representación y formarán parte de la comisión negociadora"31.

Conviene señalar, aunque volveremos sobre esta cuestión más adelante, que de lo anterior surge la segunda función clave vinculada a la noción de representatividad. En efecto, además de la representación institucional, cumple un papel fundamental en materia de negociación colectiva.

Pues bien, volviendo al criterio de la afiliación sindical, la realidad colombiana se caracteriza por una bajísima tasa de sindicali-

28 Ley 278 de 1996, Artículo 5.c) [literal modificado por el artículo 1 de la Ley 990 de 2005]: "1. Tres (3) representantes, con sus respectivos suplentes personales, designados o removidos por las Confederaciones Sindicales más representativas del país, determinadas con base en el número de afiliados que cada una de estas posea al momento de la elección, según el censo que en tal sentido elabore el Ministerio de la Protección Social".

29 Retomando las expresiones del Ministerio de Trabajo, se trata de una "invitación" que consiste en llenar un formulario online que se autodenomina "precensal, [...] con el fin de consolidar la información que permitirá realizar posteriormente el Censo Sindical para conocer el número de organizaciones activas y de sindicalistas que hay en el país". http://www.mintrabajo.gov.co/prensa/ noticias-del-ministerio/759-noviembre-2015/4974-por-el-derecho-de-asociacion-y-libertad-sindical -participe-en-el-censo-.html

30 Colombia, Decreto 160 de 2014, por el cual se reglamenta la Ley 411 de 1997 aprobatoria del Convenio 151 de la OIT, en lo relativo a los procedimientos de negociación y solución de controversias con las organizaciones de empleados públicos, 49.055 Diario Oficial, 5 de febrero de 2014. Disponible en: http://www.icbf.gov.co/cargues/avance/docs/decreto 0160 2014.htm

31 Colombia, Decreto 89 de 2014, por el cual se reglamentan los numerales 2 y 3 del artículo 374 del Código Sustantivo del Trabajo, 49.039 Diario Oficial, 20 de enero de 2014. Disponible en: http:// www.alcaldiabogota.gov.co/sisjur/normas/Norma1.jsp?i=56473 
zación del 3,4\%, y por una abstención electoral sindical altísima ${ }^{32}$. Ciertamente, estos datos evidencian un sindicalismo automarginalizado que, paradójica y proporcionalmente, como expresión de su propia debilidad y precaria visión, transita por el despeñadero del culto a la división, a la resta, a la fractura, a la dispersión, a los microsindicatos o pequeñas parcelas de realización de sectas, filiaciones o vanidades personales, y en alguna medida sin interés real en el sindicalismo.

Ese paisaje se adorna con altísimos grados de pugnacidad, conflictividad, fanatismo o maximalismo del $100 \%$, de intolerancia, de epítetos descalificatorios y ofensivos, por competencia intrasindical entre los microlíderes sindicales de los microsindicatos, lo que concentra toda la "capacidad" sindical con "olvido" de la eficacia en la contratación colectiva. Las confederaciones sindicales ${ }^{33}$ y los empleadores, en común, guardan silencio.

En todo caso, el uso del criterio de la afiliación sindical en un contexto en el cual la tasa de sindicalización muestra un nivel tan bajo, no parece ni satisfactoria ni oportuna. Desde un punto de vista más teórico, se observa cómo la afiliación sindical no sirve directamente para reconocer la representatividad de los sindicatos y, seguidamente para atribuir prerrogativas específicas. En efecto, se limita a facilitar la composición de la representación sindical en la Comisión Permanente de Concertación de Políticas Salariales y Laborales o en las comisiones de negociación con la administración pública o en el sector privado, en caso de desacuerdo entre sindicatos. No se trata por lo tanto de seleccionar sindicatos para otorgarles prerrogativas especiales, sino de repartir su peso en las negociaciones en las cuales todos los sindicatos pueden participar como veremos más adelante.

\section{B. Las carencias de la afiliación sindical}

El criterio objetivo, proporcional y democrático del grado de representatividad que puede tener un sindicato según el número de

32 Escuela Nacional Sindical. Sistema de Información Laboral y Sindical. Reporte a diciembre de 2013 (Escuela Nacional Sindical, Medellín, 2013).

33 Igualmente practican entre sí la división y la resta, la fractura y la dispersión; carecen de ideas programáticas sobre contratación colectiva y representación sindical. 
sus afiliados, se determina por las normas legales, por el principio sindical de la buena fe y la ética de legitimidad sindical, por los afiliados reales y verdaderos, que se puedan $\operatorname{probar}^{34}$.

Aparte del muy particular contexto colombiano caracterizado por un clima de violencia y persecución del movimiento sindical que obviamente la desincentiva ${ }^{35}$, el criterio de la afiliación plantea de por sí muchas dificultades ${ }^{36}$, en especial el sempiterno problema de la veracidad del número de afiliados presentado por un sindicato. El Comité de Libertad Sindical afirma que "para poder determinar de la mejor manera posible la representatividad de las organizaciones sindicales, es necesario garantizar la imparcialidad y la confidencialidad del procedimiento; por ende, la verificación de la representatividad de una organización sindical debería estar a cargo de un órgano independiente e imparcial" "37. En especial en relación con el criterio de la afiliación, considera que "una Comisión de tres (3) miembros encargada de verificar la afiliación sindical de las distintas organizaciones es compatible con los principios de libertad sindical"38; "un extracto de las cotizaciones sindicales serviría efectivamente para determinar el número de afiliados" ${ }^{39}$.

34 La representatividad sindical sí puede ser materia de prueba: sindical, administrativa o judicial. No existe el "secreto" sindical. La OIT ha señalado que los sindicatos sí pueden "probar su representatividad”. Organización Internacional del Trabajo, OIT, Comisión de Expertos, La negociación colectiva en la administración pública: un camino a seguir, Informe a la Conferencia Internacional del Trabajo, no 288, 107 (OIT, Ginebra, 2013). Disponible en: http://www.ilo.org/ilc/ILCSessions/102/ reports/reports-submitted/WCMS_205520/lang--es/index.htm

35 Guillermo Correa-Montoya, lina Paola Malagón-Díaz, Ana María Díaz, Leidy Sanjuán, José Luciano SAnín-VÁsquez \& Élver Fernando Herrera, No es muda la muerte: informe de violaciones a la vida, la libertad e integridad de las y los sindicalistas en Colombia durante el 2008 y situación de impunidad de las violaciones en el periodo 1986-2009 (2009). Disponible en: http://www.ens. org.co/index.htm, http://protectionline.org/files/2012/10/Cuaderno-de-Derechos-Humanos-N\%C2\% BA-21-de-ENS-Informe- $\%$ C2\%ABNo-es-muda-la-muerte $\% \mathrm{C} 2 \% \mathrm{BB}$-sobre-violaci $\% \mathrm{C} 3 \% \mathrm{~B} 3 \mathrm{n}$ de-derechos-humanos-de-sindicalistas-colombianos-en-el-2008-e-impunidad-de-las-violacionesdel-1986-al-2009.pdf. Igualmente, MARJORIE ZúÑIgA-Romero, El declive del sindicalismo en Colombia y sus consecuencias frente al conflicto colectivo, Revista de Derecho, Universidad del Norte, edición especial, 189-213 (2012). Disponible en: http://rcientificas.uninorte.edu.co/index. $\mathrm{php} / \mathrm{derecho/article/viewFile/3907/2836}$

36 En este sentido, los jueces franceses han afirmado que el criterio de los efectivos no puede considerarse como único criterio decisivo para reconocer o rechazar la representatividad de un sindicato. Francia, Corte de Casación, Sala de lo Social, 4 de marzo de 1970, V Bulletin des arrêts des chambres civiles, $\mathrm{n}^{\circ}$ 161. Disponible en: https://www.legifrance.gouv.fr/affichJuriJudi.do?idTexte= JURITEXT000006982289

37 Organización Internacional del Trabajo, OIT, La libertad sindical..., párrafo 351.

38 Organización Internacional del Trabajo, OIT, La libertad sindical..., párrafo 350.

39 En La libertad sindical..., párrafo 352, la OIT afirma: "no es necesario facilitar una lista con los nombres de los miembros de las organizaciones sindicales para poder determinar el número de sus afiliados". 
Obvio, para determinar la representatividad, no se puede contar como "afiliados" que solo figuren en papel por ser "objetos" simulados de tráfico, comercio o intercambio en la feria de múltiples "afiliaciones" en varios sindicatos, en el mundo delictivo de la falsedad material e ideológica, solo para obtener beneficios personales de fueros y permisos sindicales, so pretexto de la autonomía sindical. No, la autonomía sindical se explica en función del ejercicio de la actividad sindical verdadera - no la simulada-, de la democracia sindical real, de la ética y la legitimidad sindical.

Este tráfico y simulación no es sindicalismo. Es todo lo contrario: es una práctica perversa de deslegitimación social de las organizaciones sindicales. Es el abuso del derecho. Es el fraude, el delito de falsedad, oculto so pretexto del inexistente "secreto" sindical, de una mal entendida y mal utilizada autonomía sindical. Es la ausencia de principios y de ética sindical. Es el beneficio personal escudado en el interés general sindical. Es el cáncer en los sindicatos. La ética sindical contra ese tráfico de "afiliados" y contra el abuso en los permisos sindicales es el talón de Aquiles si no cesa la "competencia" y, unificadamente, las confederaciones y federaciones sindicales de empleados públicos adoptan una directriz sindical.

En materia sindical también existe el principio de reciprocidad de derechos y obligaciones, esto es, el derecho solo existe en relación con las obligaciones. Derechos y obligaciones es una unidad jurídica. No existe el derecho sin obligaciones. El derecho de afiliación sindical comporta las obligaciones de pagar la cuota sindical y asistir a asambleas. Así, es legítima la afiliación a uno o varios sindicatos, siempre y cuando se cumplan las obligaciones sindicales respectivas.

Igualmente, surge la dificultad que reside en saber a quién se tiene que entregar la información pertinente, ¿a la autoridad administrativa o al juez? ${ }^{40}$

En el contexto colombiano, facilitar este tipo de datos a la administración no resulta una opción adecuada. Así, se podría admitir que el sindicato haya de presentar al juez el número de afiliados, así como los datos permitiendo su comprobación, en caso de litigio, por ejemplo, como lo afirma la OIT, un extracto de las cotizaciones

40 Henar Álvarez-Cuesta, La mayor representatividad sindical, 111 (Universidad de León, León, 2006). 
sindicales. Parece conveniente que sea el juez quien esté encargado de recibir los datos de afiliación del sindicato ya que el respeto del secreto de afiliación y la imposibilidad de identificar personalmente a los trabajadores sin su consentimiento han de guiar los dispositivos en los cuales el juez o un organismo tercero independiente deben jugar un papel central. Pues bien, el dispositivo colombiano adoptó la posición radicalmente opuesta. El artículo 365 literal f CST relativo al registro sindical obliga al sindicato a presentar ante el Ministerio de Trabajo, la "nómina completa del personal de afiliados con su correspondiente documento de identidad"41. Esta información transmitida en el momento de constitución del sindicato no tiene por qué ser actualizada. Ciertamente, el artículo 400 CST prevé que "los empleadores respectivos deduzcan de los salarios de los trabajadores afiliados y pongan a la disposición del sindicato, el valor de las cuotas ordinarias o extraordinarias con que aquellos deben contribuir", lo que puede permitir un control actualizado del número de afiliados por parte del empleador. Sin embargo, en caso de que el sindicato prefiera recaudar de forma autónoma o en la hipótesis de que se trate de un sindicato de industria que supone la intervención de varios empleadores, la posibilidad de control del número actualizado de afiliados plantea problemas.

Si bien resulta difícil compaginar y encontrar un punto de equilibrio entre el respeto a la libertad sindical y la necesaria verificación de la realidad de las cifras proporcionadas por un sindicato, hemos de constatar que el dispositivo actual colombiano no consigue de manera efectiva cumplir ninguna de estas exigencias.

\section{Los otros criterios}

Tradicionalmente, dos vías permiten reconocer a un sindicato como representativo: o bien mediante la verificación de criterios legalmente definidos, que se denomina representatividad probada, efectiva o demostrada, o bien mediante la irradiación por afiliación

41 Modificado por el artículo 4 de la Ley 584 de 2000. Colombia, Ley 584 de 2000, por la cual se derogan y se modifican algunas disposiciones del Código Sustantivo del Trabajo, 44.043 Diario Oficial, 14 de junio de 2000. Disponible en: http://www.secretariasenado.gov.co/senado/basedoc/ ley_0584_2000.html 
a una organización sindical con mayor representatividad, que se denomina representatividad presumida.

La representatividad probada pone en marcha el principio de concordancia y conduce a medir la representatividad de un sindicato en un ámbito profesional y territorial considerado mediante la medición de unos criterios definidos, como en el caso colombiano, por medio del número de afiliados. No obstante, es posible utilizar otros criterios. El Comité de Libertad Sindical de la OIT se refiere por ejemplo a las "elecciones generales entre los trabajadores"42.

En esta línea, el ordenamiento jurídico español recurre única y exclusivamente al criterio de la audiencia electoral para medir la representatividad sindical. Sin lugar a dudas, el criterio de la audiencia electoral es el criterio cuantitativo por excelencia que permite a los trabajadores seleccionar de forma directa a los sindicatos que los representan. Considerada como "la forma de medición de la representatividad de los sindicatos [...], el factor demostrativo de la fuerza de organización, de la capacidad de negociación y de conflictos colectivos" ${ }^{43}$, la audiencia electoral constituye en España "el epicentro y el eje vertebral del sistema sindical"44. Es posible poner de relieve dos elementos característicos: por una parte, el dispositivo legal opta por un umbral numérico determinado en porcentaje y, por otra parte, estos porcentajes se miden respecto al número total de representantes del personal elegidos en el ámbito considerado $^{45}$. La opción legal de utilizar la audiencia electoral, como criterio para determinar la mayor representatividad, persigue dos objetivos: evitar el minifundismo sindical (o atomización) y buscar la centralización sindical ${ }^{46}$. Igualmente, como lo subraya el Tribunal Constitucional, TC, permite evitar el problema estructural

42 Organización Internacional del Trabajo, OIT, La libertad sindical..., párrafo 349.

43 Antonio Baylos-Grau, Representación en la empresa y audiencia electoral. Notas sobre el mecanismo representativo español, en Aspectos conflictivos de las elecciones sindicales, 11-24, 21 (María José Romero-Ródenas, coord., Bomarzo, Albacete, 2006).

44 María Emilia CaSAs-BaAmonde, Jurisprudencia constitucional y representatividad sindical, 19-20 Temas Laborales, Revista Andaluza de Trabajo y Bienestar Social, $41-79$ (1990).

45 Según los artículos 6.2.a y 7.2 LOLS, el umbral es de "10\% o más de delegados de personal de los miembros de los comités de empresa y de los correspondientes órganos de las Administraciones Públicas" en el ámbito territorial y profesional considerado. España, Ley Orgánica de Libertad Sindical, 11/1985, LOLS, 2 de agosto, 189 Boletín Oficial del Estado, BOE, 8 de agosto de 1985. Texto consolidado disponible en: https://www.boe.es/buscar/act.php?id=BOE-A-1985-16660

46 Fernando Valdés Dal-Ré, Sobre las condiciones de acreditación de un sindicato como más representativo de Comunidad Autónoma, 1 Relaciones Laborales, 1-11 (2011). 
de la baja tasa de afiliación a los $\operatorname{sindicatos}^{47}$. Ambos problemas suenan muy fuerte en el caso colombiano ${ }^{48}$.

En Francia, el criterio de la audiencia electoral se convirtió desde la reforma de 2008 en el criterio decisivo, aunque no exclusivo ${ }^{49}$. Se establece una nueva lista de siete criterios de medida de la representatividad ${ }^{50}$. Los criterios son los siguientes: el respeto de los valores republicanos; la independencia; la transparencia financiera; una antigüedad mínima de dos años; la audiencia electoral; la influencia principalmente caracterizada por la actividad y la experiencia; el efectivo de los adherentes y las cuotas. Respecto a la audiencia electoral, es preciso señalar que se modifica su apreciación relativa, ya que se prevén dos umbrales según el ámbito de negociación. En los ámbitos sectorial e interprofesional, los sindicatos han de contar con, al menos, el 8\% de los votos expresados y, en el ámbito de la empresa con, al menos, el 10\%. En caso de litigio sobre la representatividad sindical, el juez aplica de forma acumulativa todos los criterios.

En ambos ordenamientos jurídicos, coexisten en la empresa dos canales de representación: la representación sindical y la representación unitaria elegida por y entre los trabajadores de una empresa

47 España, Tribunal Constitucional, Sala Plena, Sentencia STC 98/1985, 29 de julio de 1985. Disponible en: http://hj.tribunalconstitucional.es/HJ/es/Resolucion/Show/478

48 Por ejemplo, Héctor VÁSQuEZ-FernÁNDEZ, La negociación colectiva en Colombia, en Estrategias sindicales para una mayor y mejor negociación colectiva en América Latina y Caribe. Campaña libertad sindical, negociación colectiva y autorreforma sindical, 258-291, 269 (CSA-CSI, Confederación Sindical de Trabajadores y Trabajadoras de las Américas, São Paulo, 2013).

49 Antes de la reforma de 2008, la representatividad se medía por la aplicación de criterios legales combinados y completados por la jurisprudencia. El antiguo artículo L. 133-2 Code du Travail, CT, enuncia los efectivos del sindicato, su independencia, sus cuotas, su experiencia y antigüedad y, finalmente, su actitud durante el período de ocupación nazi, en la Segunda Guerra Mundial. Señalamos que este artículo se refería concretamente a la representatividad para negociar convenios colectivos susceptibles de extensión, en su acepción francesa. Sin embargo, la jurisprudencia ha recurrido de manera general a este artículo para medir la representatividad, sea cual sea la prerrogativa sindical considerada. Igualmente, su actuación condujo a una apreciación esencialmente cualitativa que permitía verificar, desde una perspectiva subjetiva, la autenticidad y la realidad del sindicato. Francia, Código del Trabajo, CT. Disponible en: https://www.legifrance.gouv.fr/affichCode. do?cidTexte=LEGITEXT000006072050\&dateTexte=20171027. Para profundizar: JEAN-MAURICE Verdier, Syndicats et droit syndical. Traité de droit du travail, Vol. I (2e ed., Guillaume-Henri Camerlynck, dir., Dalloz, Paris, 1987).

50 Art. L. 2121-1 CT (la numeración del Código del Trabajo francés obedece a una lógica propia, según la cual la letra L corresponde a normas con rango de ley, la letra $\mathrm{D}$ a normas reglamentarias que son decretos simples y la letra $\mathrm{R}$ a decretos adoptados en Consejo de Estado. Por otra parte, la serie de dígitos permite ubicar el artículo de la manera siguiente: el primero se refiere a la Parte del Código, el segundo al Libro, el tercero al Título y el cuarto al Capítulo. El número que aparece tras el guion remite al artículo como tal). 
que permite la celebración de elecciones ${ }^{51}$. Sin embargo, la organización de elecciones para medir la representatividad sindical puede tener lugar independientemente de la existencia de ambos canales.

La representatividad presumida consiste en considerar representativos a todos los sindicatos afiliados a una central sindical considerada más representativa ${ }^{52}$. A partir de ahí, todos los sindicatos afiliados a ella son representativos en su ámbito de acción correspondiente. En España, el artículo 6.2 b) LOLS dispone que la representatividad se reconoce a "los sindicatos o entes sindicales, afiliados, federados o confederados a una organización sindical de ámbito estatal que tenga la consideración de más representativa de acuerdo con lo previsto en la letra a)". Indudablemente, el carácter de más representativo permite a una central sindical situarse en una posición privilegiada respecto de otras, de fortalecer su capacidad de representación ${ }^{53}$ y de representar institucionalmente el interés general de los trabajadores ${ }^{54}$. Un doble objetivo surge: hacer visibles determinados interlocutores viables para los poderes públicos y permitir la consolidación de los medios de acción de los sindicatos ${ }^{55}$. En efecto, las centrales sindicales más representativas disponen de una prerrogativa muy potente que se materializa por la capacidad de irradiar o contagiar su representatividad a todos los sindicatos a ella afiliados.

51 CARMEn SÁEz-LARA, La representación colectiva de los trabajadores en la empresa, 58 Revista del Ministerio de Trabajo y Asuntos Sociales, Ejemplar dedicado a XXV años del Estatuto de los Trabajadores, 315-342 (2005). Disponible en: http://www.empleo.gob.es/es/publica/pub_electronicas/ destacadas/revista/numeros/58/Est13.pdf

52 Ahora bien, la representatividad de la central sindical corresponde a una representatividad probada, en los ámbitos interprofesional y nacional.

53 Según el artículo 6.1 LOLS, "la mayor representatividad sindical reconocida a determinados sindicatos les confiere una singular posición jurídica a efectos, tanto de participación institucional como de acción sindical". El profesor Valdés escribe que "en el ordenamiento jurídico español, el factor de diferenciación sindical más importante es la mayor representatividad” y que su problema reside en los límites de su aplicación. FERNANDO VALDÉS DAL-RÉ, El sistema de diferenciación entre organizaciones sindicales: de la mayor representatividad a la suficiente implantación y representatividad, I y II, 11 (I) 1-8 y 12 (II) Relaciones Laborales, 1-9 (1993). Para el TC, el tratamiento se justifica y se legitima siempre y cuando el medio utilizado es proporcional al objetivo perseguido. España, Tribunal Constitucional, Sala Segunda, Sentencia STC 9/1986, 21 de enero de 1986. Disponible en: http:/hj.tribunalconstitucional.es/HJ/es/Resolucion/Show/572. También afirma que la mayor representatividad tiene como origen un dato objetivo que es la voluntad de los trabajadores. España, Tribunal Constitucional, Sala Plena, Sentencia STC 98/1985, 29 de julio de 1985. Disponible en: http://hj.tribunalconstitucional.es/HJ/es/Resolucion/Show/478

54 Antonio Baylos-Grau, Derecho del trabajo: modelo para armar, 132 (Editorial Trotta, Madrid, 1991).

55 Tomás Sala-Franco, El sindicato más representativo a nivel estatal. Funciones y competencia, 1 Relaciones Laborales, 365-378 (1986). 
Conviene señalar que la técnica de la representatividad presumida plantea dificultades y provoca críticas fundadas ${ }^{56}$. El principal riesgo que enfrenta es la distensión con la noción de representación que se materializa por la desconexión entre representantes y trabajadores. Este riesgo toma particular relevancia en materia de representación institucional y de negociación colectiva, en la cual la actuación de los sindicatos tiene repercusiones directas sobre las condiciones de trabajo y empleo de los trabajadores, y no tanto cuando se trata de permitir la implementación de los sindicatos en las empresas. Volveremos enseguida sobre estas cuestiones.

\section{LAS PRERROGATIVAS INHERENTES A LA REPRESENTATIVIDAD SINDICAL}

En el ámbito internacional, no cabe duda de que la noción de "representatividad" tiene una función instrumental y práctica clara. Se deriva de la presencia sindical ante órganos internacionales una función sustancial de representación de los trabajadores, la representación institucional que hemos abordado más arriba.

No obstante, surge otra prerrogativa clave directamente conectada con la representatividad: la representación convencional, es decir, la negociación colectiva y la capacidad de firmar convenio ${ }^{57}$. También hay una serie de prerrogativas adicionales que pueden variar según el ordenamiento jurídico considerado y que se refiere esencialmente a las formas de organización en la empresa, a cómo el movimiento sindical puede tejer una red y asegurar su presencia en el mayor número de empresas posible ${ }^{58}$.

Antes de abordar con más detalles esas prerrogativas, es oportuno valorar la noción de representatividad respecto al principio de igualdad entre sindicatos.

56 En este sentido, ANTONio OJEDA-AvilÉs, La representatividad sindical como excepción, 1 Relaciones Laborales, 238-252 (1992).

57 JeAn-Maurice Verdier, Sur la relation entre représentation et représentativité syndicales, 1 Droit Social, 5-10 (1991).

58 José Luis Monereo-PÉrez, Estudio preliminar, El sindicalismo y el orden democrático, en Sindicatos, Trade-Unions y corporaciones, VIII y ss. (Georges Renard, Comares, Granada, 2014). 


\section{A. La compatibilidad de la noción de representatividad con el principio de igualdad}

Como lo apunta el Comité de Libertad Sindical de la OIT, el carácter de representativo produce consecuencias como el hecho de que "podrían acordarse ciertas ventajas en materia de representación a los sindicatos, en razón de su grado de representatividad"59; "el hecho de reconocer la posibilidad de un pluralismo sindical no impediría que se concedieran ciertos derechos y ventajas a las organizaciones más representativas" ${ }^{60}$. Encontramos esta misma idea en varias recomendaciones, por ejemplo, cuando se afirma que la selección de sindicatos se realiza "con miras a determinar las organizaciones a las que han de atribuirse derechos preferentes o exclusivos"61.

Ahora bien, se precisa que la distinción entre sindicatos según su carácter más o menos representativo, "no debería tener como consecuencia el privar a las organizaciones sindicales que no hayan sido reconocidas como las más representativas, de los medios esenciales para defender los intereses profesionales de sus miembros ni del derecho de organizar su gestión y de formular su programa de acción" 62 . Así, los sindicatos sin carácter representativo, "deben poder desempeñarse y tener por lo menos, el derecho de hacerse portavoces de sus miembros y de representarlos en caso de reclamación individual"63. De hecho, se precisa que "las ventajas se limiten, de manera general, al reconocimiento de ciertos derechos preferenciales en lo que se refiere a cuestiones tales como la negociación colectiva, la consulta por las autoridades o la designación de delegados ante organismos internacionales" 64 .

Igualmente, la Comisión de Expertos de la OIT, en un documento reciente de cardinal importancia por contener una visión sistemática e integral sobre la negociación colectiva en el mundo se pronunció sobre estas cuestiones y señaló que "una distinción

59 Organización Internacional del Trabajo, OIT, La libertad sindical..., párrafo 355.

60 Organización Internacional del Trabajo, OIT, La libertad sindical..., párrafo 354.

61 Organización Internacional del Trabajo, OIT, Recomendación 159 sobre las relaciones de trabajo en la administración pública, numeral I.1 (Ginebra, 1978). Disponible en: http://www.ilo.org/dyn/ normlex/es/f?p=NORMLEXPUB:12100:0::NO::P12100_INSTRUMENT_ID:312497

62 Organización Internacional del Trabajo, OIT, La libertad sindical..., párrafo 346.

63 Organización Internacional del Trabajo, OIT, La libertad sindical..., párrafo 359.

64 Organización Internacional del Trabajo, OIT, La libertad sindical..., párrafo 354. 
entre las organizaciones sindicales más representativas y las demás organizaciones, no constituye en sí, un motivo de crítica" ${ }^{\text {"65. }}$.

Así, la conformidad de la representatividad con los principios fundamentales del derecho sindical, es decir, con los principios de igualdad entre sindicatos y de pluralismo sindical, no plantea mayor dificultad, si se garantiza a los sindicatos que no han sido reconocidos representativos, disponer de las prerrogativas nucleares de la acción sindical, es decir, la capacidad de obrar y de proteger sus afiliados.

\section{B. La negociación colectiva y la aplicación de la convención colectiva}

Ante todo, es oportuno distinguir dos aspectos relativos a la relación entre representatividad sindical y capacidad convencional: la representatividad puede permitir atribuir la capacidad convencional pero igualmente puede ser un criterio para extender la eficacia personal de la convención colectiva.

Por lo que se refiere al primer aspecto, la relación entre representatividad sindical y capacidad convencional se da en el ámbito internacional. Varios documentos de la OIT subrayan que la noción de representatividad está esencialmente ligada a la negociación colectiva. Por ejemplo, se afirma que "uno de los principios esenciales de los Convenios números 151 y 154 es la relación entre el derecho de negociación colectiva y la existencia de cierto grado de representatividad"66. "las organizaciones representativas [...] de trabajadores sean reconocidas a los efectos de la negociación colectiva" ${ }^{67}$. La Comisión de Expertos en Aplicación de Convenios afirma en el mismo sentido que "solamente las organizaciones independientes y representativas son capaces de defender eficazmente los intereses de los trabajadores"68. El Comité de Libertad

65 Organización Internacional del Trabajo, OIT, Comisión de Expertos, La negociación colectiva en la administración pública: un camino a seguir, Informe a la Conferencia Internacional del Trabajo, numeral 286, 106 (OIT, Ginebra, 2013).

66 Organización Internacional del Trabajo, OIT, Comisión de Expertos, La negociación colectiva en la administración pública..., numeral 282, 104.

67 Organización Internacional del Trabajo, OIT, Recomendación 163 sobre el fomento de la negociación colectiva, numeral II.3.a.

68 Organización Internacional del Trabajo, OIT, Comisión de Expertos, La negociación colectiva en la administración pública..., numeral 282, 104. 
Sindical permite llegar mucho más allá, al considerar compatible con la libertad sindical la exclusividad del derecho de negociación colectiva de los sindicatos más representativos, si bien estableciendo "criterios objetivos y previamente determinados a fin de evitar toda posibilidad de parcialidad o abuso" 69 .

En Colombia, no se establece estrictamente tal relación. En efecto, en el sector privado, el artículo 467 CST se refiere a "uno o varios patronos o asociaciones patronales, por una parte, y uno o varios sindicatos o federaciones sindicales de trabajadores, por la otra". En el ámbito de la negociación de los empleados públicos, de manera general, las partes negociadoras son, independientemente del nivel considerado, las mismas, es decir, representantes de la Administración considerada y representantes sindicales de los empleados públicos ${ }^{70}$. Así, resulta claro que los sindicatos, con la única exigencia de ser legalmente constituidos, son los agentes que representan los trabajadores en los procesos de negociación colectiva; no se establece ninguna exigencia relativa a su representatividad.

Ahora bien, ¿cómo el dispositivo colombiano racionaliza la intervención de los sindicatos? Dos puntos pueden ser avanzados:

Primero, la misma constitución del sindicato permite comprobar su real implantación en el ámbito considerado. En efecto, la constitución de un sindicato, sea cual sea el ámbito considerado, se condiciona a la existencia de al menos 25 trabajadores afiliados ${ }^{71}$. Sin valorar en detalles esta regla, lo que nos llevaría a extendernos más allá del objetivo de este trabajo, consideramos que parece confundir dos cuestiones distintas. Por un lado, se trata de la creación de un sindicato por el cual la fijación de un número único de 25 trabajadores parece arbitrario y excesivo ${ }^{72}$, y por otro lado, se

69 Organización Internacional del Trabajo, OIT, La libertad sindical ..., párrafo 962.

70 El Decreto 160 de 2014 utiliza esa expresión genérica "organización sindical" (artículos 1, 4.4, 6.2, 7 párr. y 9.1.), lo que comprende e incluye, sin distinción, el derecho de negociación colectiva para los sindicatos de primero, segundo y tercer grado, es decir, los sindicatos, federaciones y confederaciones. Colombia, Decreto 160 de 2014, por el cual se reglamenta la Ley 411 de 1997 aprobatoria del Convenio 151 de la OIT, en lo relativo a los procedimientos de negociación y solución de controversias con las organizaciones de empleados públicos, 49.055 Diario Oficial, 5 de febrero de 2014.

71 Artículo 359 CST: "Todo sindicato de trabajadores necesita para constituirse o subsistir un número no inferior a veinticinco (25) afiliados", declarado exequible por la Corte Constitucional. Colombia, Corte Constitucional, Sentencia C-201-02, 19 de marzo de 2002, magistrado ponente Jaime Araújo-Rentería. Disponible en: http://www.corteconstitucional.gov.co/RELATORIA/2002/C-201-02.htm

72 Conviene apuntar que desde la OIT se afirma que "el número mínimo de 30 trabajadores para la constitución de sindicatos sería admisible en los casos de sindicatos de industria, pero dicho número mínimo debería reducirse en el caso de los sindicatos de empresa, para no obstaculizar la creación 
trata de medir la capacidad de representación de un sindicato, es decir, su representatividad, por la cual la existencia de 25 afiliados podría considerarse suficiente para demostrar la presencia sindical en el ámbito considerado (aunque en el ámbito sectorial, es más dudoso). Así, se podría fijar un número de afiliados más reducido en el momento de la creación del sindicato; esto permitiría facilitar la creación de sindicatos en las empresas, y fijar un número de afiliados en porcentaje, en valor relativo respecto al número total de trabajadores, para medir su representatividad, es decir, su capacidad de representación. En todo caso, esta regla de los 25 afiliados constituye uno de los ejemplos más ilustrativos del carácter regresivo y represivo del ordenamiento legal en clara contradicción con el marco constitucional.

Segundo, podríamos afirmar que la lógica es la siguiente: todos los sindicatos presentes en el ámbito considerado pueden participar en el proceso de negociación correspondiente. La racionalización se opera mediante la autonomía sindical que conduce a un período previo de negociación entre los diferentes sindicatos afectados cuya finalidad es la constitución de una única mesa de negociación ${ }^{73}$. Esta afirmación surge de dos decretos promulgados a principios de 2014 relativos a la negociación colectiva de los empleados públicos ${ }^{74} \mathrm{y}$ a la negociación colectiva del sector privado y de los trabajadores oficiales $^{75}$. Bajo criterios objetivos, proporcionales y democráticos,

de estas organizaciones, sobre todo cuando el país tiene una importantísima proporción de pequeñas empresas y la estructura sindical se basa en el sindicato de empresa" (OIT, La libertad sindical..., párrafo 285). No es un despropósito considerar que, si bien se refiere a un número de 30 trabajadores, esta consideración de la OIT tiene vigencia en el caso colombiano.

73 Es lo que técnicamente, en el Derecho Procesal Universal, se denomina acumulación de pretensiones, como expresión de la racionalidad y economía procedimental, dentro de un procedimiento concentrado. También está en el Código de Procedimiento Civil (artículo 82), en el Código de Procedimiento Administrativo y de lo Contencioso Administrativo (artículo 165) y en el Código General del Proceso (artículo 88).

74 Decreto 160 de 2014: el legislador se limita a decir a manera de orientación, sin mucha precisión, que "el número de integrantes de la comisión negociadora sindical debe ser razonablemente proporcional al ámbito de la negociación" (artículo 9). En forma principal se aplica la autonomía sindical dirigida a la realización previa de actividades de coordinación para la integración de solicitudes con el fin de concurrir en unidad de pliego y en unidad de integración de las comisiones negociadora y asesora (artículo 8).

75 Antes del Decreto 89 de 2014, la opción escogida por el legislador era prohibir la creación de varios sindicatos de misma clase en una empresa, lo que naturalmente hacía improcedente un proceso de selección de sindicatos. Sin embargo, la Corte Constitucional declaró inexequible esta medida radical, lo que produjo la posibilidad de crear varios sindicatos en una misma empresa. Colombia, Corte Constitucional, Sentencia C-567-00, 7 de mayo de 2000, magistrado ponente Alfredo Beltrán-Sierra. Disponible en: http://www.corteconstitucional.gov.co/RELATORIA/2000/C-567-00.htm. Pos- 
de ética y legitimidad sindical, los propios sindicatos con afiliados verdaderos y en ejercicio de la autonomía podrán distribuir proporcionalmente los negociadores y determinar el número total de estos, teniendo especial cuidado en garantizar que todo sindicato cuente al menos con un negociador, principal, o en últimas suplente con presencia alternada o rotada como principal. Es el principio de la democracia, de "los principios democráticos" a los cuales están sujetos los sindicatos, por mandato constitucional ${ }^{76}$ y se aplica el principio de autonomía sindical y de no intervención de la autoridad administrativa ${ }^{77}$. Por lo tanto, en caso de incapacidad de la

teriormente, en 2008, la Corte declaró inexequible el artículo 357 numeral 2 CST, según el cual "Cuando en una misma empresa coexistiere un sindicato de base con uno gremial o de industria, la representación de los trabajadores, para todos los efectos de la contratación colectiva, corresponderá al sindicato que agrupe a la mayoría de los trabajadores de la empresa". Colombia, Corte Constitucional, Sentencia C-063-08, 30 de enero de 2008, magistrado ponente Clara Inés Vargas-Hernández. Disponible en: http://www.corteconstitucional.gov.co/RELATORIA/2008/C-063-08.htm. Esta nor$\mathrm{ma}$ ante concurrencia o pluralidad de organizaciones sindicales, para determinar la representación sindical en la contratación colectiva, opta por aplicar el criterio de mayoría y minoría de afiliados sindicales, como referente comparativo en relación con el número de trabajadores de la empresa, para que al sindicato que agrupara a la mayoría de los trabajadores de la empresa le correspondiera la representación excluyendo a los demás sindicatos minoritarios. Se consideró inexequible la norma legal de estirpe excluyente por aplicar criterios incluyentes desde la perspectiva constitucional de la libertad y autonomía sindical, lo que significa desechar el criterio de mayoría/minoría como referentes para la exclusión, y afirmar el derecho de toda organización sindical de participar en la negociación colectiva bajo el criterio de la inclusión. Consecuentemente, afirma en cuanto a la conformación de la comisión de negociación que "corresponde a las organizaciones sindicales en forma autónoma definir lo relativo a la representación". Al mismo tiempo, advierte que "la exclusión del ordenamiento jurídico de la norma acusada, no habría de conducir a la atomización de las negociaciones y al desmedro de la seguridad jurídica de las relaciones laborales, ya que no se trataría de multiplicar las negociaciones y las convenciones en función del número de sindicatos coexistentes, sino de asegurar la participación directa de cada uno de tales sindicatos en las negociaciones que conduzcan a la suscripción de la correspondiente convención colectiva de trabajo". Sin embargo, la realidad se tradujo en una mala interpretación de la posición de la Corte, al desvirtuar o deformar o abusar de la libertad y autonomía sindical, lo que implicó la multiplicación de los procesos de negociación en cada empresa en función del número de sindicatos presentes. El Decreto 89 de 2014 cambió profundamente esta lógica para llegar a la misma solución que la adoptada en la negociación de los empleados públicos.

76 Artículo 39 CPC: "La estructura interna y el funcionamiento de los sindicatos [...] se sujetarán [...] a los principios democráticos". También Colombia, Corte Constitucional, Sentencia C-797-00, 29 de junio de 2000, magistrado ponente Antonio Barrera-Carbonell. Disponible en: http://www. corteconstitucional.gov.co/RELATORIA/2000/C-797-00.htm. Colombia, Corte Constitucional, Sentencia T-251-10, 16 de abril de 2010, magistrado ponente Nilson Pinilla-Pinilla. Disponible en: http://www.corteconstitucional.gov.co/relatoria/2010/T-251-10.htm

77 Organización Internacional del Trabajo, OIT, Convenio 87 sobre la libertad sindical y la protección del derecho de sindicación, artículo 3 (San Francisco, 1948). Disponible en: http://www.ilo.org/dyn/ normlex/es/f?p=NORMLEXPUB:12100:0::NO::P12100_INSTRUMENT_ID:312232. Organización Internacional del Trabajo, OIT, Convenio 151 sobre la protección del derecho de sindicación y los procedimientos para determinar las condiciones de empleo en la administración pública, artículo 4, numerales 2.1 y 2.2 (Ginebra, 1978). Disponible en: http://www.ilo.org/dyn/normlex/es/f?p= NORMLEXPUB:12100:0::NO::P12100_INSTRUMENT_ID:312296 
autonomía sindical para racionalizar la participación sindical en el proceso de negociación, el ordenamiento jurídico colombiano introduce indirectamente la noción de representatividad vía el criterio de la afiliación sindical. En efecto, en caso de imposibilidad de acuerdo entre los distintos sindicatos, se establece que la composición de la representación sindical en la negociación se realiza por medio del principio de proporcionalidad, tomando en cuenta su representatividad según el número de afiliados ${ }^{78}$.

Esta solución conduce a formular dos observaciones: en primer lugar, el uso de la noción de representatividad resulta accesorio, lejos de la finalidad que le corresponde. En efecto, a la negociación no acceden los sindicatos representativos, sino los sindicatos como tal.

En segundo lugar, afirmamos la institucionalidad sindical dentro de la diversidad, la tolerancia y la inclusión, por medio de la democracia, lo que significa que en una sola organización sindical deben existir y convivir criterios distintos, para respetar e incluir la diferencia, bajo reglas democráticas. Por el contrario, el fundamentalismo tiene una verdad sindical única o un caudillo sindical único, que exige sindicato propio. "Quien no está conmigo, está contra mí”. Es el canibalismo sindical. Y un lenguaje dogmático, sectario y excluyente, sin capacidad de convocatoria. Por ello, la multiplicidad de organizaciones sindicales. Es la reproducción, en el mundo sindical, de la cultura de la intolerancia, heredada del estalinismo. En términos prácticos, es dividir y restar fuerzas. Es el microsindicalismo, el minifundio sindical, la parcelación sindical, la división o fraccionamiento o fractura en mil pedazos sindicales, profundamente ineficaz, uno de los culpables del escepticismo y la

78 Por lo que se refiere a la negociación de los empleados públicos, en caso de imposibilidad de llegar a un acuerdo, el artículo 9 del Decreto 160 de 2014 prevé que debe aplicarse de forma subsidiaria una regla de distribución "objetiva y proporcional al número de afiliados con derecho y pago de su cuota sindical depositada en banco conforme a los artículos 393 y 396 del Código Sustantivo de Trabajo y según certificación del tesorero y secretario". Esta lógica existe desde los inicios de la reglamentación en la materia, por ejemplo, en el decreto de 2012.

Por lo que se refiere a la negociación del sector privado, el Decreto 89 de 2014 opta, de forma principal, por la autonomía sindical y la negociación previa entre sindicatos para constituir una comisión de negociación. Luego, de forma subsidiaria, el ordenamiento jurídico establece que "si no hubiere acuerdo, la comisión negociadora sindical se entenderá integrada en forma objetivamente proporcional al número de sus afiliados y los diversos pliegos se negociarán en una sola mesa de negociación para la solución del conflicto, estando todos los sindicatos representados en el procedimiento de negociación y en la suscripción de la convención colectiva. Los sindicatos con menor grado de representatividad proporcional al número de sus afiliados, tendrán representación y formarán parte de la comisión negociadora" (artículo 1.2). 
baja tasa de sindicalización. Por el contrario, la institucionalidad sindical, el respeto a la pluralidad, la tolerancia y la inclusión en la diferencia, mediante la democracia sindical, es sumar, es eficacia sindical. Envidia de la buena, frente al capital que, como expresión de su fuerza y eficacia, practica la institucionalidad, la unidad: Fedegan, ANDI, Asobancaria, Asofondos, SAC... Ellos no se dividen.

Por lo que se refiere al segundo aspecto, es decir, la relación entre representatividad y eficacia personal de la convención colectiva, como lo advierte la OIT por intermedio de su Comisión de Expertos en Aplicación de Convenios, "los Convenios 151 y 154 [relativos a la negociación colectiva en el sector público y privado] no prevén un porcentaje obligatorio para que una organización pueda considerarse "representativa".. la cuestión del umbral de representatividad no se plantea si el sistema nacional en vigor solo autoriza a las organizaciones a negociar en nombre de sus propios afiliados; no obstante, la situación cambia cuando los acuerdos o convenios colectivos negociados por las organizaciones interesadas se aplican a todos los trabajadores de un sector o de un establecimiento, y por lo tanto, no solo a sus propios afiliados"79. Igualmente, "cuando ningún sindicato de una unidad de negociación específica reúna el porcentaje de representatividad exigido para poder negociar en nombre de todos los trabajadores, las organizaciones sindicales minoritarias deberían poder negociar de manera conjunta o separada en nombre de sus propios afiliados" $"$. Así, más que el derecho a la negociación propiamente dicho, la OIT pone en relación la representatividad con la eficacia desplegada por el producto de la negociación colectiva, asociando representatividad con eficacia general y ausencia de representatividad con eficacia limitada.

En Colombia, sobre esta cuestión, la comparación entre el sector público y la negociación del sector privado y trabajadores oficiales permite poner de relieve una paradoja ${ }^{81}$. En efecto, la regulación

79 Organización Internacional del Trabajo, OIT, Comisión de Expertos, La negociación colectiva en la administración pública..., párrafo 293, 108.

80 Organización Internacional del Trabajo, OIT, Comisión de Expertos, La negociación colectiva en la administración pública..., párrafo 295, 109.

81 Pierre-Henri Cialti, La negociación colectiva en Colombia: Una visión cruzada entre el sector público y el sector privado, 1 Revista Estudios Socio-jurídicos, Universidad del Rosario, 18, 167-202 (2016). Disponible en: https://revistas.urosario.edu.co/index.php/sociojuridicos/article/view/4415 
normativa del campo de aplicación del resultado de la negociación colectiva es distinta, según se trate del vínculo laboral contractual de los trabajadores privados y oficiales, o del vínculo laboral legal y reglamentario de los empleados públicos.

Dentro del vínculo legal y reglamentario de los empleados públicos, dada la naturaleza y carácter general de la ley y del reglamento, el acuerdo colectivo resultante de la negociación colectiva, instrumentalizado o ejecutado o implementado mediante ley o reglamento, es de aplicación general a todos los empleados públicos, según sea el ámbito de negociación: general, nacional o de contenido común, o singular o de contenido particular por entidad o territorio ${ }^{82}$.

En cambio, el campo de aplicación o de extensión de la convención colectiva en el sector privado, dada su naturaleza bilateral, contractual y dispositiva, está determinado legalmente por el grado o nivel de representatividad sindical o capacidad sindical de representación, según el sindicato afilie menos o más de la tercera parte del total de trabajadores de la empresa. Si cuenta con menos, solo se aplica a los sindicalizados y a los no sindicalizados que adhieran voluntariamente. Si cuenta con más de dos tercios, lo que no deja de ser una curiosidad aritmética poco ortodoxa respecto al principio mayoritario, se aplica a todos los trabajadores ${ }^{83}$. Así, el principio general es que cada sindicato representa a sus propios afiliados ${ }^{84}$, es decir, la representatividad de cada sindicato es objetiva en relación directa con su propio número de afiliados, su representatividad es directamente proporcional al número de afiliados como "criterio objetivo" $" 85$.

82 Artículos 7.1, 7.2 y 13.4 del Decreto 160 de 2014.

83 Artículos 470 y 471 CST.

84 Colombia, Corte Constitucional, Sentencia C-063-08, 30 de enero de 2008, magistrado ponente Clara Inés Vargas-Hernández. Disponible en: http://www.corteconstitucional.gov.co/ RELATORIA/2008/C-063-08.htm. Colombia, Corte Constitucional, Sentencia C-668-08, 2 de julio de 2008, magistrado ponente Mauricio González-Cuervo. Disponible en: http://www.corte constitucional.gov.co/RELATORIA/2008/C-668-08.htm. Encontramos esta idea en la doctrina de la OIT: Bernard Gernigon, Alberto Odero \& Horacio Guido, La negociación colectiva: normas de la OIT y principios de los órganos de control (Oficina Internacional del Trabajo, Ginebra, 2000). Disponible en: http://www.ilo.org/wcmsp5/groups/public/@ed_norm/@normes/documents/publication /wcms_087940.pdf

85 Organización Internacional del Trabajo, OIT, Recomendación 163 sobre el fomento de la negociación colectiva, numeral II 3.b (Ginebra, 1981). 
Resulta por lo tanto patente la paradoja. En efecto, si las condiciones de negociaciones respecto a los negociadores de la parte laboral son idénticas en el sector privado y en el sector público, ¿cómo se puede admitir que los efectos desplegados por el producto negociado no sean equivalentes? La ratificación por el órgano público del acuerdo firmado en el sector público no puede ser garante de su legitimidad que solo puede tener como fuente el respaldo de los trabajadores a los sindicatos firmantes.

En conclusión, parece que el dispositivo colombiano confunde de nuevo dos cuestiones: la representatividad sindical y el carácter mayoritario del acuerdo firmado.

Una perspectiva comparada puede resultar pertinente en la materia.

En Francia, es preciso distinguir la situación legal antes y después de la reforma de 2008. Antes de 2008, los sindicatos por su mera condición de representativos podían negociar y firmar un convenio colectivo. En cuanto la convención estuviera firmada por un sindicato representativo, el ordenamiento jurídico, por diversas opciones, permitía su aplicación general a todos los trabajadores incluidos en su ámbito de aplicación. La lógica era la siguiente: si la convención permite una mejora de las condiciones de trabajo, se ha de aplicar a todos los trabajadores desde el momento en que el sindicato firmante es representativo y representa, por lo tanto, el interés colectivo de la profesión. A partir de 2008, tomando en consideración la realidad económica y social en la cual la convención puede conllevar una degradación de las condiciones de trabajo, su validez se somete, además, a una exigencia de mayoría. Independientemente del ámbito considerado, se trata de una mayoría relativa, pues los sindicatos deben alcanzar un umbral del $30 \%$ de los votos en las elecciones de la representación unitaria en la empresa. Consecuentemente, la peculiaridad del sistema francés reside en la posibilidad de los sindicatos no firmantes que suman, en el mismo marco, un umbral del 50\%, de ejercer su derecho de oposición y así impedir la aplicación de la convención.

En España, el carácter de representativo condiciona tradicionalmente la facultad de acceder a las negociaciones pero no significa necesariamente la puesta en marcha efectiva del proceso de negociación. En efecto, el derecho español no se refiere únicamente a la 
noción de representatividad cuando regula la capacidad normativa de los sindicatos. La representatividad involucra una noción más amplia, la legitimación negocial, que se compone, en un primer nivel, de la exigencia de representatividad pero que, en un segundo nivel, se acompaña de una exigencia de mayoría que permite en última instancia garantizar un vínculo entre representantes y representados $^{86}$. Esta exigencia de mayoría se aplica dos veces. Una, $a$ priori al arranque de la negociación: los negociadores del convenio han de contar con la mayoría de los representantes elegidos en el ámbito considerado ${ }^{87}$. Dos, a posteriori de la negociación y antes de la firma: la mayoría de los negociadores ha de firmar el convenio. Ahora bien, para dar cumplido reconocimiento del derecho a la negociación colectiva a todos los sindicatos, tal como se desprende del artículo 37.1 de la Constitución española, $\mathrm{CE}^{88}$, se admite la validez de convenios colectivos firmados al margen de las exigencias legales (especialmente, la exigencia de mayoría de hecho), denominados extraestatutarios, a los cuales se reconoce una eficacia limitada, comparable al caso colombiano (cualquier sindicato puede negociar sin tener que demostrar su carácter representativo, ni representar una mayoría de trabajadores y firmar una convención que solo se aplica, en principio, a sus afiliados).

Esta perspectiva comparada permite poner de relieve la consideración de ambos ordenamientos jurídicos para distinguir el acceso a la negociación, en el cual el carácter representativo es clave y el producto negociado ha de cumplir una exigencia de mayoría. Esta configuración se enmarca en la voluntad de los poderes públicos

86 La representatividad permite al sindicato gozar de la legitimación inicial, básica o interviniente, que corresponde a "la facultad específica de participar efectivamente en la comisión que negociará el convenio". Tomás Sala-Franco, La negociación colectiva y los convenios colectivos, 16 (Deusto, Bilbao, 1990). Ver también, FeRmín RodRígueZ-SAÑUdo, La legitimación para negociar colectivamente (en torno al artículo 87), 100 Civitas. Revista Española de Derecho del Trabajo, 1525-1538 (2000). Para la jurisprudencia, la legitimación inicial constituye una condición previa y necesaria para poder participar en la negociación pero no constituye una condición suficiente (por ejemplo, España, Tribunal Supremo, Sentencia STS, 4 de octubre de 2001, Ar/1418 de 2002). En efecto, debe acompañarse de la legitimación plena (artículo 88 ET).

87 La mayoría de los representantes unitarios, es decir, la mayoría de los miembros de los comités de empresa o los delegados del personal incluidos en el ámbito del convenio.

88 En efecto, la jurisprudencia constitucional integró el derecho a la negociación colectiva al contenido esencial del derecho de libertad sindical, por lo que las restricciones legales en materia de negociación colectiva deberían ser consideradas inconstitucionales si no existiera una válvula de escape que permitiera garantizar el derecho a la negociación a todos los sindicatos, lo que permite la negociación extraestatutaria, es decir, al margen del dispositivo legal y que desemboca en una convención con eficacia personal limitada. 
de promover la negociación colectiva y atribuir a sus productos una eficacia general que garantiza una alta tasa de cobertura convencional sinónima de mejores condiciones de trabajo y de empleo más justas. Específicamente, el caso francés anterior a la reforma de 2008 demuestra que la representatividad sindical puede bastar para firmar convenciones colectivas aplicables a todos los trabajadores independientemente de su afiliación sindical. La función de mejora de las condiciones de trabajo asociada por entonces a la negociación colectiva explica en gran medida aquella opción legal y encuentra, sin lugar a duda, cierta aplicabilidad en el contexto colombiano.

\section{Otras funciones}

El ordenamiento jurídico colombiano no atribuye ninguna función específica a determinados sindicatos considerados representativos, a excepción de la representación institucional en la Comisión Permanente de Concertación de Políticas Salariales y Laborales. No es el caso de otros ordenamientos jurídicos, como el francés y el español. Resulta pues pertinente conocer cómo se reparten las diferentes prerrogativas sindicales en función del carácter representativo o no del sindicato considerado.

En España, conviene distinguir la mayor representatividad y la representatividad suficiente. Tampoco se pueden excluir las posibilidades de acción de los sindicatos sin representatividad.

El artículo 6.3 LOLS establece las prerrogativas de los sindicatos más representativos: la representación institucional "ante las administraciones públicas u otras entidades y organismos de carácter estatal o de comunidad autónoma que la tengan prevista", la negociación colectiva que desemboca en la firma de la convención colectiva con eficacia normativa y general, la participación en los procedimientos de consulta o negociación con las administraciones públicas en cuanto a la determinación de las condiciones de trabajo, la actuación en los mecanismos extrajudiciales de resolución de $\operatorname{conflictos}^{89}$, la capacidad de iniciar y organizar las elecciones en

89 Pierre-Henri Cialti, Los mecanismos autónomos de resolución extrajudicial de conflictos colectivos laborales: el caso español y apuntes sobre la legislación colombiana, 1 Revista de Derecho, 45, 169-211 (2016). Disponible en: http://www.scielo.org.co/pdf/dere/n45/n45a08.pdf 
las empresas y en las administraciones públicas ${ }^{90}$, la obtención de cesiones temporales de inmuebles patrimoniales públicos para su uso y "cualquier otra función representativa que se establezca". Por otra parte, aunque el artículo 6.1 LOLS no se refiere explícitamente a ella, resulta ineludible evocar la facultad otorgada a los sindicatos más representativos de irradiar su mayor representatividad a los sindicatos afiliados. Esta prerrogativa tiene una importancia fundamental, ya que permite la presencia casi automática de una representación sindical de una de las grandes centrales sindicales en numerosas empresas.

Ahora bien, la singular posición de los sindicatos más representativos y la atribución de prerrogativas especiales no pueden ir en detrimento de los sindicatos suficientemente representativos en un ámbito determinado. Así, el artículo 7.2 LOLS establece para los sindicatos suficientemente representativos, las mismas prerrogativas, excepto la participación institucional y la cesión temporal del uso de inmuebles. Sin embargo, con el fin de mantener el principio de igualdad entre los distintos sindicatos, proclamado en el artículo 2.2 LOLS $^{91}$, el Tribunal Constitucional suavizó en gran medida el alcance de la mayor representatividad. Recordó, durante el control de constitucionalidad de la LOLS, que su puesta en marcha debe ser razonable, proporcional y adecuada al objetivo perseguido ${ }^{92}$ y que

90 Pierre-Henri Cialti, La audiencia electoral como criterio de medición de la representatividad sindical: las experiencias española y francesa, 1 Revista Derecho del Trabajo, 18, 521-546 (2015).

91 La igualdad entre sindicatos resurge en materia de negociación colectiva. En efecto, el artículo 2.2.d LOLS enuncia que cada organización sindical tiene derecho a ejercer su actividad sindical y, en consecuencia, negociar en la empresa o fuera de ella. En este sentido, el TC reconoce de forma no equívoca el derecho de todos los sindicatos a la negociación colectiva de eficacia personal limitada (España, Tribunal Constitucional, Sala Plena, Sentencia STC 98/1985, 29 de julio de 1985. Disponible en: http:/hj.tribunalconstitucional.es/HJ/es/Resolucion/Show/478. España, Tribunal Constitucional, Sala Primera, Sentencia STC 107/2000, 5 de mayo de 2000. Disponible en: http:// hj.tribunalconstitucional.es/HJ/ca-ES/Resolucion/Show/SENTENCIA/2000/107. Ver también España, Tribunal Supremo, Sentencia STS, 15 de diciembre de 1994, Ar/4436 de 1995 y España, Tribunal Supremo, Sentencia STS, 14 de junio de 1999, Ar/5216. La falta de representatividad de los firmantes del convenio conduce a la no aplicación de las disposiciones del ET y, por lo tanto, a la imposibilidad de reconocer al convenio una eficacia general. FERmín Rodríguez-SAÑudo, $L a$ representatividad sindical, en Comentarios a la ley de libertad sindical, 197-218 (Miguel RodRíGUEZ-PIÑERO, coord., Tecnos, Madrid, 1986).

92 España, Tribunal Constitucional, Sala Plena, Sentencia STC 20/1985, 14 de febrero de 1985. Disponible en: http:/hj.tribunalconstitucional.es/HJ/es/Resolucion/Show/400. España, Tribunal Constitucional, Sala Plena, Sentencia STC 26/1985, 22 de febrero de 1985. Disponible en: http:/ hj.tribunalconstitucional.es/HJ/es/Resolucion/Show/406. España, Tribunal Constitucional, Sala Plena, Sentencia STC 72/1985, 13 de junio de 1985. Disponible en: http://hj.tribunalconstitucional. es/HJ/es/Resolucion/Show/452. España, Tribunal Constitucional, Sala Segunda, Sentencia STC 9/1986, 21 de enero de 1986. Disponible en: http://hj.tribunalconstitucional.es/HJ/es/Resolucion/ 
no puede conducir a impedir la presencia de otras organizaciones representativas en un ámbito determinado ${ }^{93}$. En este sentido, estimó que la participación institucional debe ser reconocida proporcionalmente a la representatividad ${ }^{94}$ y que las cesiones temporales del uso de inmuebles patrimoniales públicos han de realizarse de manera proporcional ${ }^{95}$, si bien introdujo un correctivo mediante un criterio de preferencia a los sindicatos más representativos ${ }^{96}$.

Igualmente, es oportuno precisar que el artículo 8 LOLS contempla la acción sindical en la empresa mediante las secciones sindicales que son la representación sindical constituida para ese nivel. La lógica del modelo español, como la del francés, es la siguiente: en su inmensa mayoría, los sindicatos se constituyen para el nivel supraempresarial (funcional y territorial) y despliegan su actividad en las empresas mediante secciones sindicales que pueden ser creadas con muchas facilidades. Pues bien, según el apartado 1 del artículo 8 LOLS, un mínimo de dos trabajadores afiliados a un sindicato puede constituir secciones sindicales en la empresa, celebrar reuniones, recaudar cuotas y distribuir información sin-

Show/572. España, Tribunal Constitucional, Sala Primera, Sentencia STC 39/1986, 31 de marzo de 1986. Disponible en: http://hj.tribunalconstitucional.es/HJ/es/Resolucion/Show/602

93 Por ejemplo, España, Tribunal Constitucional, Sala Plena, Sentencia STC 20/1985, 14 de febrero de 1985. Disponible en: http://hj.tribunalconstitucional.es/HJ/es/Resolucion/Show/400. España, Tribunal Constitucional, Sala Primera, Sentencia STC 184/1987, 18 de noviembre de 1987. Disponible en: http:/hj.tribunalconstitucional.es/HJ/es/Resolucion/Show/916. Para profundizar, FerNANDo VALDÉs DAL-RÉ, El sistema de diferenciación entre organizaciones sindicales: de la mayor representatividad a la suficiente implantación y representatividad, I y II, 11 (I) 1-8 y 12 (II) Relaciones Laborales, 1-9 (1993). FeRnANDo VALdés DaL-Ré, El sistema español de relaciones laborales: una aproximación, 1-2 Relaciones Laborales, 22-59 (1996). Ver también Henar Álvarez-Cuesta, La mayor representatividad sindical, 212 (Universidad de León, León, 2006). Y Juan Manuel Ramírez-Martínez, La representatividad sindical en la LOLS [Ley Orgánica de Libertad Sindical]: 25 años después, 1 Relaciones Laborales, 347-364 (2011).

94 En la práctica, permite que un sindicato representativo en un sector de actividad o en un ámbito territorial que no sea estatal o autonómico, pueda participar en los órganos de carácter consultivo instaurados en el sector o ámbito considerado (España, Tribunal Constitucional, Sala Primera, Sentencia STC 184/1987, 18 de noviembre de 1987). Para profundizar: Laura Mora-Cabello DE Alba, La participación institucional del sindicato (Consejo Económico y Social, Madrid, 2008).

95 España, Tribunal Constitucional, Sala Segunda, Sentencia STC 99/1983, 16 de noviembre de 1983. Disponible en: http://hj.tribunalconstitucional.es/HJ/es/Resolucion/Show/227. España, Tribunal Constitucional, Sala Plena, Sentencia STC 98/1985, 29 de julio de 1985. Disponible en: http:// hj.tribunalconstitucional.es/HJ/es/Resolucion/Show/478

96 Para profundizar, España, Tribunal Constitucional, Sala Plena, Sentencia STC 75/1992, 14 de mayo de 1992. Disponible en: http://hj.tribunalconstitucional.es/HJ/es/Resolucion/Show/1962. Ver también, Tomás Sala-Franco, El sindicato más representativo a nivel estatal. Funciones y competencia, 1 Relaciones Laborales, 365-378 (1986). Fernando VALDÉs DaL-RÉ, El sistema de diferenciación entre organizaciones sindicales: de la mayor representatividad a la suficiente implantación y representatividad, I y II, 11 (I) 1-8 y 12 (II) Relaciones Laborales, 1-9 (1993). Henar Álvarez-Cuesta, La mayor representatividad sindical, 198 (Universidad de León, León, 2006). 
dical y recibir la información de su sindicato. Según su apartado 2, las secciones sindicales de los sindicatos representativos o más representativos tienen derecho a disponer de "tablón de anuncios que deberá situarse en el centro de trabajo y en lugar donde se garantice un adecuado acceso al mismo de los trabajadores", a la negociación colectiva a cuyo producto se le atribuye eficacia general y a la "utilización de un local adecuado en el que puedan desarrollar sus actividades en aquellas empresas o centros de trabajo con más de 250 trabajadores".

En Francia, desde la reforma de 2008, el carácter representativo centra esencialmente su papel en la negociación colectiva, lo que conduce a aproximar las prerrogativas de todos los sindicatos independientemente de su carácter representativo en las demás materias.

En primer lugar, no basta con que el sindicato sea legalmente constituido. En efecto, para beneficiarse de las prerrogativas sindicales básicas, todos los sindicatos deben respetar los siguientes criterios de representatividad: respecto de los valores republicanos, la independencia, la antigüedad de al menos dos años y tener un ámbito geográfico y profesional que incluye la empresa considerada. En este caso, pueden desarrollar un movimiento de huelga, convocar las elecciones de la representación del personal en la empresa, presentarse a la primera vuelta de estas elecciones y constituir una sección sindical en la empresa ${ }^{97}$ y nombrar un representante de la sección sindical cuyas prerrogativas son limitadas. Es preciso apuntar que estas prerrogativas se reconocen a los sindicatos afiliados a las organizaciones representativas en el ámbito nacional e interprofesional, en el esquema de la representatividad por irradiación.

En segundo lugar, los sindicatos representativos, además de las prerrogativas anteriores, tienen derecho a un local propio en las empresas de más de 1000 trabajadores. Pueden designar en la empresa a un delegado sindical dotado de un estatuto protector privilegiado y de varias prerrogativas, especialmente la capacidad convencional lo que permite afirmar que solo los sindicatos representativos pueden negociar una convención colectiva. Igualmente, disponen de un monopolio para depositar un preaviso de huelga en las empresas de servicios públicos. Finalmente, las confederaciones sindicales

97 Article L. 2142-1 CT. 
representativas nacionales e interprofesionales pueden designar representantes en varios organismos como el Consejo Económico y Social, la Comisión Nacional de la Negociación Colectiva, los Consejos de Administración de las Cajas de Seguridad Social, etc. 


\section{CONCLUSIóN}

Como apunta el profesor Fernando Valdés Dal-Ré, "la representatividad es una noción polisémica, susceptible de apropiarse diversos sentidos" $" 98$. Igualmente, su alcance y su significado en cada ordenamiento varían y no se configuran de forma unívoca. Este estudio demuestra, en cualquier caso, que hay un problema jurídico en el ordenamiento colombiano. En efecto, aparece una antinomia, una falta de coherencia entre el marco constitucional que promueve la acción sindical en un Estado Social de Derecho y su concreción legal que no establece ningún mecanismo garantizador de esta acción. Al contrario, conduce a entorpecerla y obstaculizarla. Así, más que considerar que "el derecho laboral colectivo [es] el encargado de regular las relaciones laborales entre los trabajadores sindicalizados y sus patronos"99, podría constituir el elemento vertebral de la puesta en marcha del Estado Social de Derecho en el ámbito de las relaciones laborales que permita el diálogo entre empresarios y todos los trabajadores con independencia de su vínculo de afiliación. En este sentido, recurrir a la noción de representatividad podría ser un primer paso para fortalecer el papel de los sindicatos, actores ineludibles de la democracia en el ámbito de las relaciones laborales.

La perspectiva comparada, sin pretender aportar soluciones inmediatamente extrapolables, demuestra, primero, que cada ordenamiento establece mecanismos que favorecen la presencia sindical en las empresas. Obviamente, el hecho de que el tejido sindical sea constituido por sindicatos de rama o de ámbito territorial afiliados a centrales sindicales facilita esa implementación en la escala empresarial. En todo caso, cumplen con el marco constitucional que, como en Colombia, reconoce una importancia fundamental al sindicato en el mundo de las relaciones laborales y en la sociedad en general. Igualmente, la noción de representatividad sindical juega un papel fundamental en materia de negociación colectiva, lo que asegura su realidad práctica sinónima de mejoras de las condiciones

98 Fernando VAldés DAL-RÉ, El sistema de diferenciación entre organizaciones sindicales: de la mayor representatividad a la suficiente implantación y representatividad, I y II, 11 (I) 1-8 y 12 (II) Relaciones Laborales, 1-9 (1993).

99 María de Jesús Illera-SANTos, Cambios normativos en el derecho laboral colectivo a partir de la Constitución de 1991, 16 Revista de Derecho de la División de Ciencias Jurídicas, 45-61 (2001). Disponible en: http://rcientificas.uninorte.edu.co/index.php/derecho/article/viewFile/2934/2014 
de trabajo, y simboliza la atribución de prerrogativas sindicales extensas que garantizan el cumplimiento de las labores sindicales en las empresas. Finalmente, desde el punto de vista del derecho internacional, hay que admitir que el dispositivo colombiano cumple con los estándares básicos en la materia, con los mínimos que se pueden esperar de un Estado democrático. Sin embargo, limita fuertemente el uso de la noción de representatividad al restringirla a la representación institucional, lo que no deja de plantear dudas respecto al encaje constitucional del dispositivo legal. 


\section{BIBLIOGRAFÍA}

\section{Libros}

Álvarez-Cuesta, Henar, La mayor representatividad sindical (Universidad de León, León, 2006).

Baylos-Grau, Antonio, Derecho del trabajo: modelo para armar (Editorial Trotta, Madrid, 1991).

Comisión de Expertos en Aplicación de Convenios, La negociación colectiva en la administración pública: un camino a seguir (Oficina Internacional del Trabajo, Ginebra, 2013). Disponible en: http://www.ilo.org/wcmsp5/groups/public/--ed_norm/---relconf/documents/meetingdocument/wcms_205520.pdf

Correa-Montoya, Guillermo, Malagón-Díaz, Lina Paola; Díaz, Ana María; Sanjuán, Leidy; Sanín-Vásquez, José Luciano \& Herrera, Élver Fernando, No es muda la muerte: informe de violaciones a la vida, la libertad e integridad de las y los sindicalistas en Colombia durante el 2008 y situación de impunidad de las violaciones en el período 1986-2009 (2009). Disponible en: http://protectionline. org/files/2012/10/Cuaderno-de-Derechos-Humanos-N\%C2\%BA-21-de-ENSInforme- $\% \mathrm{C} 2 \% \mathrm{ABNo}$-es-muda-la-muerte $\% \mathrm{C} 2 \% \mathrm{BB}$-sobre-violaci $\% \mathrm{C} 3 \% \mathrm{~B} 3 \mathrm{n}$ de-derechos-humanos-de-sindicalistas-colombianos-en-el-2008-e-impunidadde-las-violaciones-del-1986-al-2009.pdf

Cueva, Mario de la, Nuevo derecho mexicano del trabajo, Tomo II (Porrúa, México, 1986).

Escuela Nacional Sindical, ENS, Sistema de Información Laboral y Sindical. Reporte a diciembre de 2013 (Escuela Nacional Sindical, Medellín, 2013).

García-Murcia, Joaquín, Organizaciones sindicales y empresariales más representativas: posición jurídica y dimensión política (Ministerio de Trabajo y de la Seguridad Social, Madrid, 1987).

Gernigon, Bernard; Odero, Alberto \& Guido, Horacio, La negociación colectiva: normas de la OIT y principios de los órganos de control (Oficina Internacional del Trabajo, Ginebra, 2000). Disponible en: http://www.ilo.org/wcmsp5/groups/ public/@ed_norm/@normes/documents/publication/wcms_087940.pdf

Mora-Cabello de Alba, Laura, La participación institucional del sindicato (Consejo Económico y Social, Madrid, 2008).

Navarro-Nieto, Federico, La representatividad sindical (Ministerio de Trabajo y de la Seguridad Social, Madrid, 1993).

Organización Internacional del Trabajo, OIT, La libertad sindical - Recopilación de decisiones y principios del Comité de Libertad Sindical del Consejo de Administración de la OIT (5 $5^{\mathrm{a}}$ ed., OIT, Ginebra, 2006). Disponible en: http:// www.ilo.org/global/docs/WCMS_090634/lang--es/index.htm

Organización Internacional del Trabajo, OIT, Comisión de Expertos, La negociación colectiva en la administración pública: un camino a seguir, Informe a la Conferencia Internacional del Trabajo (OIT, Ginebra, 2013). Disponible en: http://www.ilo. org/ilc/ILCSessions/102/reports/reports-submitted/WCMS_205520/lang--es/ 
index.htm

SAla-Franco, Tomás, La negociación colectiva y los convenios colectivos (Deusto, Bilbao, 1990).

Verdier, Jean-Maurice, Syndicats et droit syndical. Traité de droit du travail, Vol. I ( $2^{\mathrm{e}}$ ed., Guillaume-Henri Camerlynck, dir., Dalloz, Paris, 1987).

Yannakourou, Stamatina, L'Etat, l'autonomie collective et le travailleur: étude comparée $d u$ droit italien et du droit français de la représentativité syndicale (Librairie générale de droit et de jurisprudence, LGDJ, Paris, 1995).

\section{Colaboración en obras colectivas}

Baylos-Grau, Antonio, Representación en la empresa y audiencia electoral. Notas sobre el mecanismo representativo español, en Aspectos conflictivos de las elecciones sindicales, 11-24 (María José Romero-Ródenas, coord., Bomarzo, Albacete, 2006).

Monereo-Pérez, José Luis, Estudio preliminar, El sindicalismo y el orden democrático, en Sindicatos, Trade-Unions y corporaciones (Georges Renard, Comares, Granada, 2014).

Rodríguez-Sañudo, Fermín, La representatividad sindical, en Comentarios a la ley de libertad sindical, 197-218 (Miguel Rodríguez-PiÑERo, coord., Tecnos, Madrid, 1986).

Sala-Franco, Tomás, El sindicato más representativo a nivel estatal. Funciones y competencia, 1 Relaciones Laborales, Tomo I, 365-378 (1986).

VÁsquez-Fernández, Héctor, La negociación colectiva en Colombia, en Estrategias sindicales para una mayor y mejor negociación colectiva en América Latina y Caribe. Campaña libertad sindical, negociación colectiva y autorreforma sindical, 258-291 (CSA-CSI, Confederación Sindical de Trabajadores y Trabajadoras de las Américas, São Paulo, 2013). Disponible en: http://www.ilo.org/wcmsp5/groups/ public/---ed_dialogue/---actrav/documents/publication/wcms_230682.pdf

\section{Revistas}

Casas-Baamonde, María Emilia, Jurisprudencia constitucional y representatividad sindical, 19-20 Temas Laborales, Revista Andaluza de Trabajo y Bienestar Social, 41-79 (1990).

Casas-Baamonde, María Emilia, Representatividad y mayor representatividad de los sindicatos en España. ¿Un modelo en crisis?, 33 Civitas. Revista Española de Derecho del Trabajo, 71-86 (1988).

Cialti, Pierre-Henri, La audiencia electoral como criterio de medición de la representatividad sindical: las experiencias española y francesa, 1 Revista Derecho del Trabajo, 18, 521-546 (2015).

Cialti, Pierre-Henri, La negociación colectiva en Colombia: una visión cruzada entre el sector público y el sector privado, 1 Revista Estudios Socio-jurídicos, Universidad 
del Rosario, 18, 167-202 (2016). Disponible en: https://revistas.urosario.edu.co/ index.php/sociojuridicos/article/view/4415

Cialti, Pierre-Henri, Los mecanismos autónomos de resolución extrajudicial de conflictos colectivos laborales: el caso español y apuntes sobre la legislación colombiana, 1 Revista de Derecho, 45, 169-211 (2016). Disponible en: http://www.scielo.org.co/ pdf/dere/n45/n45a08.pdf

CRUZ-Villalón, Jesús, La representatividad sindical y empresarial en las relaciones laborales y en el sistema politico español, 1 Relaciones Laborales, 151-196 (2005). Disponible en: https://idus.us.es/xmlui/handle/11441/41763?locale-attribute $=\mathrm{es}$

Fernández-Alonso, EduArdo, El juez laboral y la jurisprudencia constitucional sobre el derecho de asociación, 34 Revista de Derecho Público, Universidad de los Andes, 3-22 (2015). Disponible en: https://derechopublico.uniandes.edu.co/components/ com_revista/archivos/derechopub/pub511.pdf

Illera-Santos, María de Jesús, Cambios normativos en el derecho laboral colectivo a partir de la Constitución de 1991, 16 Revista de Derecho de la División de Ciencias Jurídicas, 45-61 (2001). Disponible en: http://rcientificas.uninorte.edu.co/index. php/derecho/article/viewFile/2934/2014

Ojeda-Avilés, Antonio, La representatividad sindical como excepción, 1 Relaciones Laborales, 238-252 (1992).

Ramírez-Martínez, JuAn Manuel, La representatividad sindical en la LOLS [Ley Orgánica de Libertad Sindical]: 25 años después, 1 Relaciones Laborales, 347364 (2011).

Rodríguez-Sañudo, Fermín, La legitimación para negociar colectivamente (en torno al artículo 87), 100 Civitas. Revista Española de Derecho del Trabajo, 1525-1538 (2000).

Sáez-Lara, Carmen, La representación colectiva de los trabajadores en la empresa, 58 Revista del Ministerio de Trabajo y Asuntos Sociales, Ejemplar dedicado a XXV años del Estatuto de los Trabajadores, 315-342 (2005). Disponible en: http://www. empleo.gob.es/es/publica/pub_electronicas/destacadas/revista/numeros/58/ Est13.pdf

VALdÉs DAL-RÉ, Fernando, El sistema de diferenciación entre organizaciones sindicales: de la mayor representatividad a la suficiente implantación y representatividad, I y II, 11 (I) 1-8 y 12 (II) Relaciones Laborales, 1-9 (1993).

VALDÉS DAL-RÉ, FeRnANDo, El sistema español de relaciones laborales: una aproximación, 1-2 Relaciones Laborales, 22-59 (1996).

VAldÉs Dal-RÉ, Fernando, Representación y representatividad sindicales en España, 14-15 Relaciones Laborales, 55-69 (1988).

VAldés DAL-Ré, Fernando, Sobre las condiciones de acreditación de un sindicato como más representativo de Comunidad Autónoma, 1 Relaciones Laborales, 1-11 (2011).

VERDIER, JEAN-MAURICE, Sur la relation entre représentation et représentativité syndicales, 1 Droit Social, 5-10 (1991).

ZúÑiga-Romero, MARJorie, El declive del sindicalismo en Colombia y sus consecuencias frente al conflicto colectivo, Revista de Derecho, Universidad del Norte, edición 
especial, 189-213 (2012). Disponible en: http://rcientificas.uninorte.edu.co/index. php/derecho/article/viewFile/3907/2836

\section{Normatividad internacional}

España, Constitución española, CE, 311 Boletín Oficial del Estado, BOE, 29 de diciembre de 1978. Texto original y texto consolidado disponibles en: http://www.boe.es/ buscar/act.php?id=BOE-A-1978-31229

España, Real Decreto Legislativo 1/1995, de 24 de marzo, por el que se aprueba el texto refundido de la Ley del Estatuto de los Trabajadores, ET, 75 Boletín Oficial del Estado, BOE, 29 de marzo de 1995. Texto consolidado y actualizado disponible en: https://www.boe.es/buscar/act.php?id=BOE-A-1995-7730

España, Ley Orgánica de Libertad Sindical, 11/1985, LOLS, 2 de agosto, 189 Boletín Oficial del Estado, BOE, 8 de agosto de 1985. Texto consolidado disponible en: https://www.boe.es/buscar/act.php?id=BOE-A-1985-16660

Francia, Código del Trabajo, CT. Disponible en: https://www.legifrance.gouv.fr/ affichCode.do?cidTexte $=$ LEGITEXT000006072050\&dateTexte $=20171027$

Organización Internacional del Trabajo, OIT, Constitución de la Organización Internacional del Trabajo de 1919 (Oficina Internacional del Trabajo, Ginebra, 2010). Disponible en: http://www.ilo.org/dyn/normlex/es/ $\mathrm{f} ? \mathrm{p}=1000: 62: 0::$ NO:62:P62_LIST_ENTRIE_ID:2453907:NO

Organización Internacional del Trabajo, OIT, Convenio 87 sobre la libertad sindical y la protección del derecho de sindicación (San Francisco, 1948). Disponible en: http://www.ilo.org/dyn/normlex/es/f?p=NORMLEXPUB:12100:0::NO: :P12100_INSTRUMENT_ID:312232

Organización Internacional del Trabajo, OIT, Convenio 151 sobre la protección del derecho de sindicación y los procedimientos para determinar las condiciones de empleo en la administración pública (Ginebra, 1978). Disponible en: http:// www.ilo.org/dyn/normlex/es/f?p=NOR MLEXPUB:12100:0::NO::P12100_ INSTRUMENT_ID:312296

Organización Internacional del Trabajo, OIT, Recomendación 159 sobre las relaciones de trabajo en la administración pública (Ginebra, 1978). Disponible en: http:// www.ilo.org/dyn/normlex/es/f?p=NOR MLEXPUB:12100:0::NO::P12100_ INSTRUMENT_ID:312497

Organización Internacional del Trabajo, OIT, Recomendación 163 sobre el fomento de la negociación colectiva (Ginebra, 1981). Disponible en: http://www.ilo.org/ dyn/normlex/es/f?p=NORMLEXPUB:12100:0::NO::P12100_ILO_CODE:R163

\section{Normatividad colombiana}

Colombia, Constitución Política, versión corregida 116 Gaceta Constitucional, 20 de julio de 1991. Disponible en: http://www.secretariasenado.gov.co/senado/basedoc/ constitucion_politica_1991.html 
Colombia, Decreto 1092/2012, por el cual se reglamentan los artículos 7 y 8 de la Ley 411 de 1997 en lo relativo a los procedimientos de negociación y solución de controversia con las organizaciones de empleados públicos, 48.440 Diario Oficial, 24 de mayo de 2012. Disponible en: http://mintrabajo.gov.co/normatividad-mayodecretos-2012/1442-decreto-1092-del-24-de-mayo-de-2012-.html

Colombia, Decreto 89 de 2014, por el cual se reglamentan los numerales 2 y 3 del artículo 374 del Código Sustantivo del Trabajo, 49.039 Diario Oficial, 20 de enero de 2014. Disponible en: http://www.alcaldiabogota.gov.co/sisjur/normas/Norma1. jsp?i $=56473$

Colombia, Decreto 160 de 2014, por el cual se reglamenta la Ley 411 de 1997 aprobatoria del Convenio 151 de la OIT, en lo relativo a los procedimientos de negociación y solución de controversias con las organizaciones de empleados públicos, 49.055 Diario Oficial, 5 de febrero de 2014. Disponible en: http://www.icbf.gov. co/cargues/avance/docs/decreto_0160_2014.htm

Colombia, Decreto Ley 3743 de 1950, Código Sustantivo del Trabajo, 27.622 Diario Oficial, 7 de junio de 1951. Disponible en: http://www.secretariasenado.gov.co/ senado/basedoc/codigo_sustantivo_trabajo.html

Colombia, Ley 278 de 1996, 30 de abril, Comisión permanente de concertación de políticas salariales y laborales creada por el artículo 56 de la Constitución Política, 42.783 Diario Oficial, 10 de mayo de 1996. Disponible en: http://www. secretariasenado.gov.co/senado/basedoc/ley_0278_1996.html

Colombia, Ley 584 de 2000, por la cual se derogan y se modifican algunas disposiciones del Código Sustantivo del Trabajo, 44.043 Diario Oficial, 14 de junio de 2000. Disponible en: http://www.secretariasenado.gov.co/senado/basedoc/ ley_0584_2000.html

Colombia, Ley 990 de 2005, por la cual se modifica el literal c) del artículo 5 de la Ley 278 de 1996, 46.046 Diario Oficial, 29 de septiembre de 2005. Disponible en: http:// www.secretariasenado.gov.co/senado/basedoc/ley_0990_2005.html

Colombia, Ley 1444 de 2011, por medio de la cual se escinden unos Ministerios, se otorgan precisas facultades extraordinarias al Presidente de la República para modificar la estructura de la Administración Pública y la planta de personal de la Fiscalía General de la Nación y se dictan otras disposiciones. 48.059 Diario Oficial, 4 de mayo de 2011. Disponible en: http://www.secretariasenado.gov.co/ senado/basedoc/ley_1444_2011.html

\section{Jurisprudencia internacional}

España, Tribunal Constitucional, Sala Segunda, Sentencia STC 99/1983, 16 de noviembre de 1983. Disponible en: http://hj.tribunalconstitucional.es/HJ/es/Resolucion/ Show/227

España, Tribunal Constitucional, Sala Plena, Sentencia STC 20/1985, 14 de febrero de 1985. Disponible en: http://hj.tribunalconstitucional.es/HJ/es/Resolucion/ Show/400

España, Tribunal Constitucional, Sala Plena, Sentencia STC 26/1985, 22 de febrero de 1985. Disponible en: http://hj.tribunalconstitucional.es/HJ/es/Resolucion/ 
Show/406

España, Tribunal Constitucional, Sala Plena, Sentencia STC 72/1985, 13 de junio de 1985. Disponible en: http://hj.tribunalconstitucional.es/HJ/es/Resolucion/Show/452

España, Tribunal Constitucional, Sala Plena, Sentencia STC 98/1985, 29 de julio de 1985. Disponible en: http://hj.tribunalconstitucional.es/HJ/es/Resolucion/Show/478

España, Tribunal Constitucional, Sala Segunda, Sentencia STC 9/1986, 21 de enero de 1986. Disponible en: http://hj.tribunalconstitucional.es/HJ/es/Resolucion/ Show $/ 572$

España, Tribunal Constitucional, Sala Primera, Sentencia STC 39/1986, 31 de marzo de 1986. Disponible en: http://hj.tribunalconstitucional.es/HJ/es/Resolucion/ Show/602

España, Tribunal Constitucional, Sala Primera, Sentencia STC 184/1987, 18 de noviembre de 1987. Disponible en: http://hj.tribunalconstitucional.es/HJ/es/Resolucion/ Show/916

España, Tribunal Constitucional, Sala Plena, Sentencia STC 75/1992, 14 de mayo de 1992. Disponible en: http://hj.tribunalconstitucional.es/HJ/es/Resolucion/Show/1962

España, Tribunal Constitucional, Sala Primera, Sentencia STC 107/2000, 5 de mayo de 2000. Disponible en: http://hj.tribunalconstitucional.es/HJ/ca-ES/Resolucion/ Show/SENTENCIA/2000/107

España, Tribunal Supremo, Sentencia STS, 15 de diciembre de 1994, Ar/4436 de 1995.

España, Tribunal Supremo, Sentencia STS, 14 de junio de 1999, Ar/5216.

España, Tribunal Supremo, Sentencia STS, 4 de octubre de 2001, Ar/1418 de 2002.

Francia, Corte de Casación, Sala de lo Social, 4 de marzo de 1970, V Bulletin des arrêts des chambres civiles, $\mathrm{n}^{\circ}$ 161. Disponible en: https://www.legifrance.gouv.fr/ affichJuriJudi.do?idTexte=JURITEXT000006982289

\section{Jurisprudencia colombiana}

Colombia, Corte Constitucional, Sentencia C-567-00, 7 de mayo de 2000, magistrado ponente Alfredo Beltrán-Sierra. Disponible en: http://www.corteconstitucional. gov.co/RELATORIA/2000/C-567-00.htm

Colombia, Corte Constitucional, Sentencia C-797-00, 29 de junio de 2000, magistrado ponente Antonio Barrera-Carbonell. Disponible en: http://www. corteconstitucional.gov.co/RELATORIA/2000/C-797-00.htm

Colombia, Corte Constitucional, Sentencia C-201-02, 19 de marzo de 2002, magistrado ponente Jaime Araújo-Rentería. Disponible en: http://www.corteconstitucional. gov.co/RELATORIA/2002/C-201-02.htm

Colombia, Corte Constitucional, Sentencia C-063-08, 30 de enero de 2008, magistrado ponente Clara Inés Vargas-Hernández. Disponible en: http://www. corteconstitucional.gov.co/RELATORIA/2008/C-063-08.htm

Colombia, Corte Constitucional, Sentencia C-668-08, 2 de julio de 2008, magistrado ponente Mauricio González-Cuervo. Disponible en: http://www. 
corteconstitucional.gov.co/RELATORIA/2008/C-668-08.htm

Colombia, Corte Constitucional, Sentencia T-251-10, 16 de abril de 2010, magistrado ponente Nilson Pinilla-Pinilla. Disponible en: http://www.corteconstitucional. gov.co/relatoria/2010/T-251-10.htm

\section{Direcciones web}

http://www.mintrabajo.gov.co/prensa/noticias-del-ministerio/759-noviembre-2015/4974por-el-derecho-de-asociacion-y-libertad-sindical-participe-en-el-censo-.html 
